Article

\title{
Differentiating Co-Delivery of Bisphosphonate and Simvastatin by Self-Healing Hyaluronan Hydrogel Formed by Orthogonal "Clicks": An In-Vitro Assessment
}

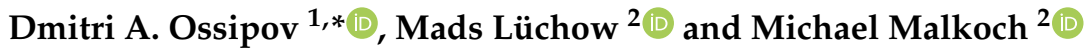 \\ 1 Department of Biosciences and Nutrition, Karolinska Institutet, SE-141 83 Stockholm, Sweden \\ 2 Department of Fiber and Polymer Technology, KTH Royal Institute of Technology, \\ SE-100 44 Stockholm, Sweden; luchow@kth.se (M.L.); malkoch@kth.se (M.M.) \\ * Correspondence: dmitri.ossipov@ki.se
}

Citation: Ossipov, D.A.; Lüchow, M.; Malkoch, M. Differentiating Co-Delivery of Bisphosphonate and Simvastatin by Self-Healing Hyaluronan Hydrogel Formed by Orthogonal "Clicks": An In-Vitro Assessment. Polymers 2021, 13, 2106 https://doi.org/10.3390/ polym13132106

Academic Editor: Alexander Böker

Received: 4 June 2021

Accepted: 23 June 2021

Published: 26 June 2021

Publisher's Note: MDPI stays neutral with regard to jurisdictional claims in published maps and institutional affiliations.

Copyright: (C) 2021 by the authors Licensee MDPI, Basel, Switzerland. This article is an open access article distributed under the terms and conditions of the Creative Commons Attribution (CC BY) license (https:// creativecommons.org/licenses/by/ $4.0 /)$
Abstract: Due to its unique properties resembling living tissues, hydrogels are attractive carriers for the localized and targeted delivery of various drugs. Drug release kinetics from hydrogels are commonly controlled by network properties and the drug-network interactions. However, and simultaneously, the programmable delivery of multiple drugs with opposing properties (hydrophilicity, molecular weight, etc.) from hydrogels with determined network properties is still challenging. Herein, we describe the preparation of injectable self-healing hyaluronic acid (HA) hydrogels that release hydrophobic simvastatin and hydrophilic aminobisphosphonate (BP) drugs independently in response to acidic and thiol-containing microenvironments, respectively. We apply a prodrug strategy to BP by conjugating it to HA via a self-immolative disulfide linker that is stable in the blood plasma and is cleavable in the cytoplasm. Moreover, we utilize HA-linked BP ligands to reversibly bind $\mathrm{Ca}^{2+}$ ions and form coordination hydrogels. Hydrazone coupling of hydrophobic ligands to HA permits the encapsulation of simvastatin molecules in the resulting amphiphilic HA derivative and the subsequent acid-triggered release of the drug. The conjugation of BP and hydrophobic ligands to HA enables preparation of both bulk self-healing hydrogels and nanogels. Moreover, the developed hydrogel system is shown to be multi-responsive by applying orthogonally cleavable linkers. The presented hydrogel is a potential candidate for the combination treatment of osteoporosis and bone cancers as well as for bone tissue regeneration since it can deliver bone anabolic and anti-catabolic agents in response to bone diseases microenvironments.

Keywords: hyaluronan; bisphosphonate; prodrug; simvastatin; hydrogel; orthogonal reactions

\section{Introduction}

In the treatment of bone diseases, it is desirable to provide both bone anabolic and anti-catabolic treatments. For example, in bone cancer that occurs after the metastasizing of a primary tumor [1], cancer cells and bone-resorbing cells (osteoclasts) act in concert [2], and it is recommended to augment chemotherapy with anti-osteoclastic drugs that prevent bone resorption [3]. Aminobisphosphonates and estrogens have a significant effect on bone remodeling by inhibiting bone breakdown and, thus, represent the main medications for the treatment of osteoporosis [4]. Recently, it was also proposed to treat osteoporosis with bone anabolic agents that increase bone mass in contrast to anti-osteoclastic drugs, the prolonged intake of which lower bone turnover [5]. A combined therapy of bisphosphonates with agents that stimulate osteoblastic function should greatly increase bone mass and prevent osteoporotic fractures [6-8]. However, bisphosphonates (BPs) are highly hydrophilic molecules, whereas most anti-cancer drugs, estrogens, and agents with bone anabolic effect such as statins and hormone prostaglandin $\mathrm{E}_{2}\left(\mathrm{PGE}_{2}\right)$ are poorly soluble in water. The co-delivery of drugs with such opposing physical properties with controlled release kinetics is a challenge. 
Hydrogels are a particularly attractive class of biomaterials for the controlled delivery of various drugs due to their tunable physical properties, programmed degradability, and ability to protect labile drugs, properties that can be controlled through the molecular design of polymer networks [9-11].

Bisphosphonates were known as anti-osteoporotic drugs for more than forty years based on their suppressing effect on bone resorbing cells, osteoclasts [12]. However, bisphosphonates fail to restore the initial bone density and architecture since, at best, they stop bone resorption but cannot stimulate bone growth. On the other hand, statins, inhibitors of 3-hydroxy-3-methylglutaryl-coenzyme reductase, were reported in several studies to induce an increase of bone mineral density (BMD) [13,14] through inhibiting the expression of matrix metalloproteases and promoting osteoblast differentiation [15]. This bone anabolic effect of statins, however, was not shown in some other in vivo studies, which was explained by poor aqueous solubility of statins and their low concentration at the bone site [16]. Based on very high affinity of BPs to the hydroxyapatite mineral part of bone, they were also utilized as bone targeting groups in the conjugation of BPs to different molecules (polymers, proteins, low molecular weight therapeutics) and nanoparticulate carriers for drugs [17]. Considering the perspectives concerning the combination of antiresorptive and bone-inducing agents, nanotechnology-based bone targeting drug delivery systems are urgently needed.

Hyaluronic acid (HA) is a natural glycosaminoglycan which is found in connective tissues and plays an important role as a signaling molecule in cell proliferation and motility, extracellular matrix organization, and morphogenesis [18]. Due to its biodegradability, biocompatibility, and non-immunogenicity, HA hydrogels were studied as localized and systemic drug delivery vehicles [19] for a variety of medical applications including bone tissue engineering [20], the curing of osteoporosis [7,8], and treatment of bone cancer [21].

To address unmet needs in nanotechnology-based drug delivery vehicles for bone diseases, we sought to make aminobisphosphonates acting simultaneously for three important purposes: (i) to act as bone targeting groups; (ii) to be released intact and act as anti-osteoclastic/anti-cancer drugs; and (iii) to enable immobilization of anabolic bone agents into localized hydrogel biomaterials for their subsequent sustained release at the bone resorbing sites. Most of the studies concerned with the targeting of nanomedicines to bone have explored covalent attachment of BP ligands without mechanisms of their intact release. To the best of our knowledge, there have been only few reports on aminobisphosphonate conjugation via releasable intact linkages [22,23]. Here, we report on the development of a hydrogel platform for the bone-targeted delivery of aminobisphosphonates and statins based on a combination of prodrug strategy and physical encapsulation of hydrophobic drugs (Figure 1). To achieve this, we conjugated pamidronate (amino-BP) and hydrophobic ligands to the hydrophilic backbone of hyaluronic acid using chemoselective orthogonal reactions. Conjugation of hydrophilic amino-BP and hydrophobic ligands to HA provides self-assembling properties of the resulting conjugate and enables encapsulation of hydrophobic cargos in the core of the generated nanoparticles. Moreover, orthogonal conjugation chemistry ensures the differential release of the drugs. For the first time, we designed the release of aminobisphosphonates intact in the cytoplasmic microenvironment and the release of simvastatin under acidic conditions that are characteristic for the bone resorption sites. Moreover, we utilize coordination binding of the attached BPs to metal cations, metal oxides, and inorganic salts nanoparticles to transform the nanoparticles into self-healing bulk hydrogels and show that the hydrogels can disassemble under acidic and reducing conditions. Our modular assembly approach, based on "clickable" chemical reactions and orthogonal release mechanisms, is generic and can be extended to a broad range of anti-cancer drugs and metal ions/coordination nanoparticles with multifunctional magnetic, electrical, and imaging properties. 


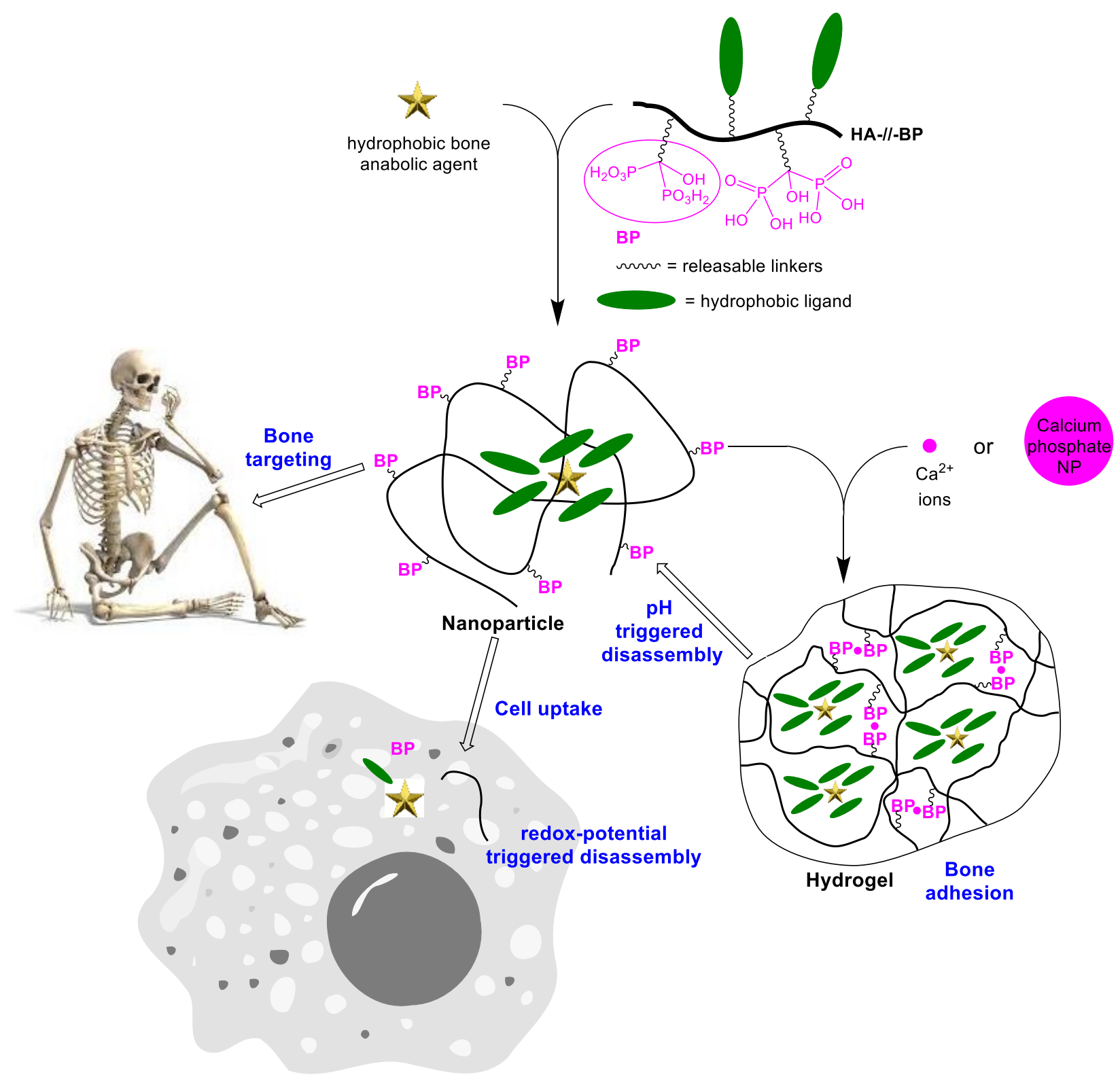

Figure 1. The nanomedicine platform based on the self-assembly of hyaluronic acid conjugated to bisphosphonates and hydrophobic ligands through orthogonally releasable linkers. Hydrophobic encapsulation of bone anabolic agents occurs during the self-assembly and provide nanoparticles with a dual mode of bioactivity.

\section{Materials and Methods}

Hyaluronic acid (HA) sodium salt (MW $150 \mathrm{kDa}$ ) was purchased from Lifecore Biomedical (Chaska, MN, USA). 1-Ethyl-3-(3-dimethylaminopropyl) carbodiimide (EDC) and $\mathrm{N}$-hydroxybenzotriazole (HOBt) were purchased from Fluka (Buchs, Switzerland). DL-dithiothreitol (DTT) was purchased from Aldrich Chemical Co (St. Louis, MO, UAS). $N, N^{\prime}$-disuccinimidyl carbonate (DSC) and simvastatin (SIM) was purchased from ACROS Organics ${ }^{\mathrm{TM}}$ (Fair Lawn, NJ, USA). 2-mercaptopyridine and 1-fluoro-2,4-dinitrobenzene were purchased from Alfa Aesar TM. 2-hydroxy-1-methyl-ethyl mercaptan 1 [24] and N(6-aminohexyl)-2,4-dinitroaniline hydrochloride [25] were synthesized according to the literature. Aldehyde-modified hyaluronic acid (HA-al) [26], thiol-modified hyaluronic acid (HA-SH) [26], HA dually modified with thiol and hydrazide groups (hy-HA-SH) [27], and HA dually modified with bisphosphonate and thiol groups (BP-HA-SH) [28] were synthesized according to our previously published protocols. All solvents were of analytical 
quality (p.a.) and were dried over $4 \AA$ molecular sieves. Dialysis membranes Spectra/Por 6 (3500 g/mol cutoff) were purchased from VWR international. ${ }^{1} \mathrm{H}-\mathrm{NMR}$ spectra were recorded in $\mathrm{D}_{2} \mathrm{O}$ with a Bruker NMR spectrometer at a magnetic field strength $9.4 \mathrm{~T}$, operating at $400 \mathrm{MHz}$. UV-Vis absorption spectra were recorded using UV-Vis spectrometer (Cary 300 Bio from Varian).

\subsection{Synthesis of 2-(2-Pyridyldithio)-2-Methylethanol 2}

2-mercaptopyridine $(504.4 \mathrm{mg}, 4.538 \mathrm{mmol})$ was dissolved in dry dichloromethane $(5 \mathrm{~mL})$ and cooled down to $0-5{ }^{\circ} \mathrm{C}$. A solution of sulfonyl chloride $(680 \mathrm{mg}, 5.037 \mathrm{mmol})$ in dry DCM $(5 \mathrm{~mL})$ was added dropwise over a period of $8 \mathrm{~min}$ to the stirred and cooled solution of 2-mercaptopyridine. Yellow precipitate was formed and the mixture was stirred at room temperature in a nitrogen atmosphere for $2.5 \mathrm{~h}$. The mixture was concentrated on a rotary evaporator and the solid yellow residue was resuspended in $5 \mathrm{~mL}$ of dry DCM. The suspension was cooled down on an ice bath and a solution of 2-hydroxy-1-methyl-ethyl mercaptan 1 (417.5 mg, $4.538 \mathrm{mmol})$ in dry DCM $(2 \mathrm{~mL})$ was subsequently added to the stirred and cold suspension in two portions over a period of $5 \mathrm{~min}$. The resulting mixture was stirred at room temperature overnight. After the reaction, the mixture was evaporated, re-suspended in $3 \mathrm{~mL}$ of DCM, and treated with 4-(dimethylamino)pyridine (582 mg, $4.765 \mathrm{mmol}$ ). The deprotonated product was purified by silica gel column chromatography using $0-5 \%$ ethanol in dichloromethane as an eluent. Yield-848 $\mathrm{mg}(92.9 \%) .{ }^{1} \mathrm{H}-\mathrm{NMR}$ $\left(\mathrm{CDCl}_{3}\right): 8.51(1 \mathrm{H}, \mathrm{d}, 2$-pyridyl, $J=5.0 \mathrm{~Hz}), 7.59(1 \mathrm{H}, \mathrm{td}, 2$-pyridyl, $J=8.0 \mathrm{~Hz}, J=1.9 \mathrm{~Hz})$, $7.41(1 \mathrm{H}, \mathrm{d}, 2$-pyridyl, $J=8.0 \mathrm{~Hz}), 7.17(1 \mathrm{H}, \mathrm{m}, 2$-pyridyl $), 3.70\left(1 \mathrm{H}, \mathrm{d},-\mathrm{CH}_{2}-, J=10.4 \mathrm{~Hz}\right)$, $3.41\left(1 \mathrm{H}, \mathrm{dd},-\mathrm{CH}_{2}-, J_{\text {gem }}=12.3 \mathrm{~Hz}, J_{\text {vic }}=7.9 \mathrm{~Hz}\right), 3.12(1 \mathrm{H}, \mathrm{m},-\mathrm{C} \underline{\mathrm{H}}<), \overline{32}(3 \mathrm{H}, \mathrm{d}$, methyl, $J=7 \mathrm{~Hz})$.

\subsection{Synthesis of 2-(2-Pyridyldithio)-2-Methylethyl N-Hydroxysuccinimide Carbonate 3}

2-(2-pyridyldithio)-2-methylethanol $2(215 \mathrm{mg}, 1.07 \mathrm{mmol})$ was dissolved in dry acetonitrile $(11 \mathrm{~mL}) . N, N^{\prime}$-disuccinimidyl carbonate $(548.2 \mathrm{mg}, 2.14 \mathrm{mmol})$ was dissolved in a mixture of dry acetonitrile $(9 \mathrm{~mL})$, dry pyridine $(1 \mathrm{~mL})$, and triethylamine $(216.1 \mathrm{mg}$, $2.14 \mathrm{mmol})$. DSC solution was added to the solution of $\mathbf{1}$ under stirring and nitrogen atmosphere. The resulting reaction mixture was stirred at room temperature in a nitrogen atmosphere for $24 \mathrm{~h}$. The mixture was evaporated to dryness and the residue was purified by silica gel column flash chromatography using $0-10 \%$ ethyl acetate in dichloromethane as an eluent. Yield-276 mg (75.4\%). ${ }^{1} \mathrm{H}-\mathrm{NMR}\left(\mathrm{CDCl}_{3}\right): 8.50(1 \mathrm{H}, \mathrm{d}, 2$-pyridyl, $J=4.8 \mathrm{~Hz})$, $7.70(2 \mathrm{H}, \mathrm{d}, 2$-pyridyl, $J=4.4 \mathrm{~Hz}), 7.13(1 \mathrm{H}, \mathrm{q}, 2$-pyridyl, $J=4.6 \mathrm{~Hz}), 4.50\left(1 \mathrm{H}, \mathrm{dd},-\mathrm{CH}_{2}\right.$,

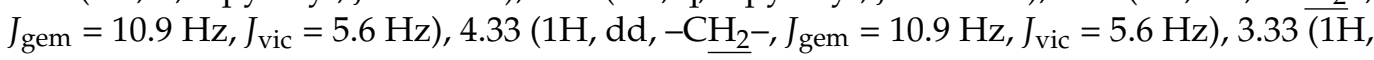
$\mathrm{m},-\mathrm{C} \underline{\mathrm{H}}<), 2.86(4 \mathrm{H}, \mathrm{s}$, succinimide $), 1.43(3 \mathrm{H}, \overline{\mathrm{d}}$, methyl, $J=7.0 \mathrm{~Hz})$.

\subsection{Synthesis of Releasable 2-Pyridyldithio Derivative of Pamidronate 4}

Pamidronate hydrochloride $(66 \mathrm{mg}, 0.243 \mathrm{mmol}$ ) was re-suspended in $1.4 \mathrm{~mL}$ of water and triethylamine $(103 \mu \mathrm{L}, 0.74 \mathrm{mmol})$ was added to the suspension to solubilize the starting bisphosphonate. Carbonate $3(141.2 \mathrm{mg}, 0.4126 \mathrm{mmol})$ was separately dissolved in acetonitrile $(2 \mathrm{~mL})$ and the pamidronate solution was added dropwise to the solution of carbonate 3 under stirring. The obtained clear reaction solution was stirred for $20 \mathrm{~h}$ and then concentrated on a rotary evaporator to remove acetonitrile. The concentrated turbid aqueous solution was washed with diethyl ether $(3 \times 7 \mathrm{~mL})$ and the cleared aqueous phase was separated and evaporated to dryness. The oily residue was washed with acetone, and the formed precipitate was isolated by centrifugation and dried. Yield- $140.5 \mathrm{mg}(75.3 \%)$. ${ }^{1} \mathrm{H}$-NMR $\left(\mathrm{D}_{2} \mathrm{O}\right): 8.26(1 \mathrm{H}, \mathrm{d}, 2$-pyridyl), $7.82(2 \mathrm{H}, \mathrm{d}, 2$-pyridyl), $7.25(1 \mathrm{H}, \mathrm{q}, 2$-pyridyl), 4.00-3.80 (2H, m, $\left.-\mathrm{CH}\left(\mathrm{CH}_{3}\right) \mathrm{CH}_{2}-\right), 3.26-3.19\left(3 \mathrm{H}, \mathrm{m},-\mathrm{C} \mathrm{H}<\right.$ and $\left.-\mathrm{NHCH}_{2}-\right), 3.09(18 \mathrm{H}, \mathrm{q}$, $-\mathrm{CH}_{2}$-from three $\mathrm{Et}_{3} \mathrm{NH}^{+}$cations), $2.00\left(2 \mathrm{H}, \mathrm{m},-\mathrm{CH}_{2} \mathrm{CH}\left(\mathrm{PO}_{3}{ }^{2-}\right)_{2}\right), 1.21(3 \mathrm{H}, \mathrm{d}$, methyl), $1.18\left(27 \mathrm{H}, \mathrm{t},-\mathrm{CH}_{3}\right.$ from three $\mathrm{Et}_{3} \mathrm{NH}^{+}$cations $)$. 


\subsection{Synthesis of 2-Pyridyldithio Derivative of N-(6-Aminohexyl)-2,4-Dinitroaniline 5}

$\mathrm{N}$-(6-aminohexyl)-2,4-dinitroaniline hydrochloride $(174 \mathrm{mg}, 0.51 \mathrm{mmol})$ dissolved in a mixture of dry acetonitrile $(2 \mathrm{~mL})$, dry pyridine $(2 \mathrm{~mL})$, and triethylamine $(210 \mu \mathrm{L}$, $1.5 \mathrm{mmol})$. Carbonate $3(102.7 \mathrm{mg}, 0.3 \mathrm{mmol}$ ) was separately dissolved in dry acetonitrile $(2 \mathrm{~mL})$ and was mixed with the solution of the amine under stirring. The mixture was stirred under a nitrogen atmosphere and room temperature for $6 \mathrm{~h}$, evaporated, and co-evaporated with toluene. The crude material was separated by silica gel column flash chromatography using $20 \%$ ethyl acetate in dichloromethane as an eluent. Yield-128.3 mg $(80 \%) .{ }^{1} \mathrm{H}-\mathrm{NMR}$ $\left(\mathrm{CDCl}_{3}\right)$ : $9.16(1 \mathrm{H}, \mathrm{d}, 2,4$-dinitroaniline residue, $J=2.5 \mathrm{~Hz}), 8.57\left(1 \mathrm{H}, \mathrm{m},-\mathrm{C}(\mathrm{O}) \mathrm{NH}-{ }^{-}\right)$, $8.46(1 \mathrm{H}, \mathrm{d}, 2$-pyridyl, $J=4.1 \mathrm{~Hz}), 8.29\left(1 \mathrm{H}, \mathrm{dd}, 2,4\right.$-dinitroaniline residue, ${ }^{2} J=9.4 \mathrm{~Hz}$, $\left.{ }^{3} J=2.5 \mathrm{~Hz}\right), 7.74(1 \mathrm{H}, \mathrm{d}, 2$-pyridyl, $J=8.1 \mathrm{~Hz}), 7.65\left(1 \mathrm{H}, \mathrm{td}, 2\right.$-pyridyl, ${ }^{2} J=7.5 \mathrm{~Hz},{ }^{3} J=$ $1.7 \mathrm{~Hz}), 7.10\left(1 \mathrm{H}, \mathrm{dd}, 2\right.$-pyridyl, $\left.{ }^{2} J=7.5 \mathrm{~Hz},{ }^{3} \mathrm{~J}=4.7 \mathrm{~Hz}\right), 6.93(1 \mathrm{H}, \mathrm{d}, 2,4$-dinitroaniline residue, $J=9.4 \mathrm{~Hz}), 4.74(1 \mathrm{H}, \mathrm{m},-\mathrm{NH}-), 4.22-4.16\left(2 \mathrm{H}, \mathrm{m},-\mathrm{CH}\left(\mathrm{CH}_{3}\right) \mathrm{CH}_{2}-\right), 3.43(2 \mathrm{H}, \mathrm{q}$, $\left.-\mathrm{C}(\mathrm{O}) \mathrm{NHCH}_{2}-, J=7.1 \mathrm{~Hz}\right), 3.26-3.17\left(3 \mathrm{H}, \mathrm{m},-\mathrm{C} \underline{\mathrm{H}}<\right.$ and $\left.-\mathrm{CH}_{2} \mathrm{NH}-\right), \overline{1.79}(2 \mathrm{H}$, quintet, $\left.-\mathrm{C}(\mathrm{O}) \mathrm{NHC}_{2} \overline{\mathrm{CH}}_{2}-, J=7.2 \mathrm{~Hz}\right), 1.58-1.39\left(6 \mathrm{H}, \mathrm{m},-\mathrm{CH}_{2} \mathrm{CH}_{2} \overline{\mathrm{CH}}_{2}-\right), 1.35(3 \mathrm{H}, \mathrm{d}$, methyl, $J=7.0 \mathrm{~Hz})$.

\subsection{Synthesis of Aldehyde-Modified DN Derivative 6}

$\mathrm{N}$-(6-aminohexyl)-2,4-dinitroaniline (DN, $303.2 \mathrm{mg}, 0.89 \mathrm{mmol}$ ) was dissolved in a mixture of dry pyridine and dry acetonitrile $(7 \mathrm{~mL}, 1: 1 \mathrm{v} / \mathrm{v})$ in the presence of triethylamine $(410 \mu \mathrm{L}, 2.965 \mathrm{mmol})$. para-formylbenzoic acid $N$-hydroxysuccinimide ester $(146.6 \mathrm{mg}$, $0.593 \mathrm{mmol}$ ) was separately dissolved in dry acetonitrile $(3.5 \mathrm{~mL})$, and the obtained solution was added dropwise into the stirred solution of DN over $5 \mathrm{~min}$. The obtained reaction solution was stirred under nitrogen atmosphere and room temperature for $4 \mathrm{~h}$ and then evaporated. After co-evaporation with toluene and dichloromethane, the crude mixture was separated by silica gel column chromatography using $20 \%$ ethyl acetate in dichloromethane as an eluent. Yield-278 mg. ${ }^{1} \mathrm{H}-\mathrm{NMR}\left(\mathrm{CDCl}_{3}\right): 10.10(1 \mathrm{H}, \mathrm{s}$, aldehyde), $9.16(1 \mathrm{H}, \mathrm{d}, 2,4$-dinitroaniline residue, $J=2.7 \mathrm{~Hz}), 8.59(1 \mathrm{H}, \mathrm{m},-\mathrm{C}(\mathrm{O}) \mathrm{N} \underline{\mathrm{H}}-), 8.29(1 \mathrm{H}, \mathrm{dd}$, 2,4-dinitroaniline residue, $\left.{ }^{2} J=9.6 \mathrm{~Hz},{ }^{3} \mathrm{~J}=2.7 \mathrm{~Hz}\right), 7.95-7.92(4 \mathrm{H}, \mathrm{m}, 1,4$-phenylene), 6.93 $(1 \mathrm{H}, \mathrm{d}, 2,4$-dinitroaniline residue, $J=9.6 \mathrm{~Hz}), 6.27(1 \mathrm{H}, \mathrm{m},-\mathrm{NH}-), 3.55-3.42(4 \mathrm{H}, 2 \times \mathrm{q}$, $-\mathrm{C}(\mathrm{O}) \mathrm{NHCH}_{2}-$ and $-\underline{\left.\mathrm{CH}_{2} \mathrm{NH}-\right)}, 1.87-1.49\left(8 \mathrm{H}, \mathrm{m},-\mathrm{CH}_{2} \mathrm{CH}_{2} \mathrm{CH}_{2} \mathrm{CH}_{2}-\right)$.

\subsection{Synthesis of Releasable HA-//-BP Conjugate}

Thiol-modified hyaluronic acid HA-SH $(40 \mathrm{mg}, 0.1 \mathrm{mmol}$ of disaccharide repeat units, $14 \mu \mathrm{mol}$ of thiol groups) was dissolved in deionized water $(5 \mathrm{~mL})$ whereas reagent 4 $(16.4 \mathrm{mg}, 14 \mu \mathrm{mol})$ was dissolved in $1 \mathrm{~mL}$ of water. The aqueous solution of 4 was added into the HA-SH solution and $\mathrm{pH}$ of the combined solution was adjusted to 7.5 with $1 \mathrm{M}$ $\mathrm{NaOH}$. The reaction was continued under stirring for $25 \mathrm{~h}$. The mixture was transferred into a dialysis tube $\left(\mathrm{M}_{\mathrm{W}}\right.$ cutoff $\left.=3500\right)$. After three dialysis rounds, firstly against acidified water $(\mathrm{pH} 4)$ containing $0.1 \mathrm{M} \mathrm{NaCl}(1 \times 2 \mathrm{~L})$ and then against acidified water $(2 \times 2 \mathrm{~L})$, the solution was lyophilized to give $31 \mathrm{mg}$ of HA-//-BP (yield-77.5\%). The incorporation of $\mathrm{BP}$ groups via disulfide linker was verified by ${ }^{1} \mathrm{H}-\mathrm{NMR}$.

\subsection{Synthesis of Releasable BP-HA-//-DN Conjugate and Its Characterization by Dynamic Light} Scattering (DLS)

Hyaluronic acid dually modified with bisphosphonate and thiol groups (BP-HA-SH) (38.7 $\mathrm{mg}, ~ 10 \mu \mathrm{mol}$ of thiol groups) was dissolved in deionized water $(4 \mathrm{~mL})$ and $\mathrm{pH}$ of the obtained solution was nuetralized with $1 \mathrm{M} \mathrm{NaOH}(60 \mu \mathrm{L})$. Reagent $5(9.2 \mathrm{mg}, 17 \mu \mathrm{mol})$ was dissolved in $0.5 \mathrm{~mL}$ of $\mathrm{N}$-methylpyrrolidone (NMP) and the obtained solution was added to BP-HA-SH solution which resulted in precipitation of the reagent. To homogenize the mixture, $3.5 \mathrm{~mL}$ of NMP was added to the mixture and the cleared reaction solution was stirred at room temperature for $23 \mathrm{~h}$. The mixture was transferred into a dialysis tube $\left(\mathrm{M}_{\mathrm{w}}\right.$ cutoff $\left.=3500\right)$ and dialyzed initially against DMSO $(1 \times 200 \mathrm{~mL})$ for $90 \mathrm{~min}$ and then against water $(4 \times 2 \mathrm{~L})$ for overall period of two days. After filtration of the dialyzed 
solution through a cotton, it was obtained $39.8 \mathrm{mg}$ of BP-HA-//-DN (yield-99.5\%). The incorporation of BP groups via disulfide linker was verified by ${ }^{1} \mathrm{H}-\mathrm{NMR}$.

\subsection{Synthesis of hy-HA-//-BP Derivative}

Hyaluronic acid dually modified with hydrazide and thiol groups (hy-HA-SH) (40 mg, $0.1 \mathrm{mmol}$ of disaccharide repeat units, $\sim 10 \mu \mathrm{mol}$ of thiol groups and $\sim 8 \mu \mathrm{mol}$ of hydrazide groups) was dissolved in deionized water $(5 \mathrm{~mL})$. Reagent $4(12.2 \mathrm{mg}, 10 \mu \mathrm{mol})$ was dissolved in $750 \mu \mathrm{L}$ of water and added to the solution of hy-HA-SH. pH of the combined solution was adjusted to 7.5 with $1 \mathrm{M} \mathrm{NaOH}$. The reaction solution was stirred for $22 \mathrm{~h}$ and then transferred into a dialysis tube $\left(\mathrm{M}_{\mathrm{W}}\right.$ cutoff $\left.=3500\right)$ and dialyzed firstly against acidified water $(\mathrm{pH} 4)$ containing $0.1 \mathrm{M} \mathrm{NaCl}(1 \times 2 \mathrm{~L})$ and then against acidified water $(2 \times 2 \mathrm{~L})$. After three dialysis rounds, the solution was freeze-dried to produce $38 \mathrm{mg}$ of hy-HA-//-BP (yield-95\%). The incorporation of BP and availability of intact hydrazide groups was verified by gel tests with $\mathrm{CaCl}_{2}$ and $\mathrm{HA}$-al derivatively, respectively.

\subsection{Synthesis of DN-hyd-HA-//-BP Derivative and Simvastatin Loading}

hy-HA-/ /-BP derivative (20 mg, $4 \mu \mathrm{mol}$ of hydrazide groups) was dissolved in $1 \mathrm{~mL}$ of water and $1 \mathrm{~mL}$ of DMSO was added to the solution. The reagent $6(4.8 \mathrm{mg}, 10.1 \mu \mathrm{mol})$ was dissolved in $2 \mathrm{~mL}$ of DMSO and added to the solution of hy-HA-//-BP. The reaction was continued for the next $24 \mathrm{~h}$. The reaction solution was transferred into a dialysis tube $\left(\mathrm{M}_{\mathrm{W}}\right.$ cutoff $\left.=3500\right)$ and dialyzed against DMSO $(2 \times 200 \mathrm{~mL}$ and $1 \times 100 \mathrm{~mL})$ until no free reagent 6 was detected in the dialysate. The dialyzed against DMSO colorless solution $(10 \mathrm{~mL})$ was divided into two equal parts $(2 \times 5 \mathrm{~mL})$. One part was directly transferred into a dialysis tube $\left(\mathrm{M}_{\mathrm{W}}\right.$ cutoff $\left.=3500\right)$ and dialyzed against water $(2 \mathrm{~L}, \mathrm{pH} 7.4$ adjusted with $1 \mathrm{M} \mathrm{NaOH})$. At the same time, $1 \mathrm{mg}$ of simvastatin was dissolved in another part of the dialyzed DMSO solution and the solution was further dialyzed against water for $24 \mathrm{~h}$. The dialysis was repeated for $4 \mathrm{~h}$ for the both SIM-loaded and non-loaded DN-hyd-HA//-BP. The dialyzed against water turbid solutions were freeze-dried providing $9.1 \mathrm{mg}$ of DN-hyd-HA-//-BP and 8.6 mg of SIM@DN-hyd-HA-//-BP.

\subsection{Formation of $\mathrm{HA}-/ /-\mathrm{BP} \bullet \mathrm{Ca}^{2+}$ Hydrogel and Its Thiol-Triggered Dissolution}

Hydrogel samples of $200 \mu \mathrm{L}$ by volume and concentrations of HA-//-BP and $\mathrm{Ca}^{2+}$ ions being $3 \% w / v$ and $0.2 \mathrm{M}$ respectively were prepared. For this purpose, $175 \mu \mathrm{L}$ solution of $\mathrm{HA}-/ /$-BP with concentration $3.4 \%$ was prepared and neutralized with $1 \mathrm{M} \mathrm{NaOH}$ and the solution was diluted with water until $185.4 \mu \mathrm{L}$. $14.6 \mu \mathrm{L}$ of the $2.75 \mathrm{M} \mathrm{CaCl}_{2}$ solution was subsequently added to the neutralized HA-//-BP solution which resulted in immediate gel formation. The hydrogel was homogenized with a pipette tip.

\subsection{Formation of $D N-/ /-H A-B P \bullet C a^{2+} H y d r o g e l$}

$3.3 \mathrm{mg}$ of DN-//-HA-BP was dissolved within $15 \mathrm{~min}$ in $100 \mu \mathrm{L}$ water providing $3.3 \%$ of a very viscous and opaque solution. $8 \mu \mathrm{L}$ of the $2.75 \mathrm{M} \mathrm{CaCl}_{2}$ solution was added to $\mathrm{DN}-/ /$-HA-BP solution which resulted in gel formation. For neutralization, $2 \mu \mathrm{L}$ of $1 \mathrm{M}$ $\mathrm{NaOH}$ was added to the gel which was homogenized with a pipette tip. The final volume of the mixture was $110 \mu \mathrm{L}$ and concentrations of DN-//-HA-BP and $\mathrm{Ca}^{2+}$ ions were $3 \%$ and $0.2 \mathrm{M}$, respectively.

\subsection{Study of DN Release from $D N-/ /-H A-B P \bullet C a^{2+}$ Hydrogel}

$\mathrm{DN}-/ /$-HA-BP•Ca ${ }^{2+}$ hydrogel with average mass of $100 \mathrm{mg}$ was incubated in either $0.5 \mathrm{~mL}$ of $0.17 \mathrm{M} \mathrm{NaCl}$ solution containing $2.5 \mathrm{mM} \mathrm{CaCl}_{2}$ and $20 \mathrm{mM}$ dithiothreitol (DTT) or $0.5 \mathrm{~mL}$ of $0.17 \mathrm{M} \mathrm{NaCl}$ solution containing $2.5 \mathrm{mM} \mathrm{CaCl}_{2}$. In $24 \mathrm{~h}$ the incubation media were replaced with the fresh ones of the same composition and the collected release media were analyzed by RP-HPLC using a gradient of buffer B from 0 to $100 \%$ over $30 \mathrm{~min}$ (buffer A: $50 \mathrm{mM}$ triethylammonium acetate (TEAA), $\mathrm{pH}$ 6.5; buffer B: $50 \% \mathrm{MeCN}$ in $50 \mathrm{mM}$ 
TEAA, $\mathrm{pH}$ 6.5). The detection was done at $363 \mathrm{~nm}$. Number of examined hydrogel samples was three per group (incubation with or without DTT).

\subsection{Study of Simvastatin Release from SIM@DN-//-HA-BP•Ca ${ }^{2+}$ Nanogel}

$1.5 \mathrm{mg}$ of SIM@DN-hyd-HA-//-BP was dissolved in $400 \mu \mathrm{L}$ of $0.1 \mathrm{M} \mathrm{NaOAc} / \mathrm{AcOH}$ $\mathrm{pH}=5.0$ buffer, whereas another $1.5 \mathrm{mg}$ of SIM@DN-hyd-HA-//-BP was dissolved in $400 \mu \mathrm{L}$ of $1 \times$ PBS buffer $\mathrm{pH}=7.4$. The dissolved samples were transferred into dialysis bags with a 3500 Da cut off and dialyzed against $5 \mathrm{~mL}$ of the same buffer. The released media were collected at determined equal time intervals $(24 \mathrm{~h})$ and the dialysis bags were placed in fresh media $(5 \mathrm{~mL})$ of the same content and $\mathrm{pH}$. The collected media were analyzed by RP-HPLC using a gradient of buffer B from 0 to $100 \%$ over 30 min followed by elution with $100 \%$ buffer B for $5 \mathrm{~min}$ (buffer A: $50 \mathrm{mM}$ triethylammonium acetate (TEAA), $\mathrm{pH}$ 6.5; buffer B: $90 \% \mathrm{MeCN}$ in $50 \mathrm{mM}$ TEAA, $\mathrm{pH} 6.5)$. The detection was done at $246 \mathrm{~nm}$. The experiments were performed in triplicate.

\subsection{Statistical Analysis}

All released data are presented as mean \pm standard deviation (SD). Each release experiment was repeated at least three times. Statistical analysis was performed using the statistical software Origin 6.1.

\section{Results and Discussion}

\subsection{Synthesis of Releasable HA-//-BP Conjugate}

Previously, we prepared hyaluronan (HA) derivatives in which aminobisphosphonates were permanently attached to HA backbone through stable chemical bonds, thereby excluding possibility for the release of aminobisphosphonates as intact drugs [29,30]. It was also demonstrated that these HA-BP derivatives formed shear-thinning and self-healing hydrogels upon interaction with either hydrated metal ions such as $\mathrm{Ca}^{2+}[31], \mathrm{Mg}^{2+}$ [32], $\mathrm{Ag}^{+}$[33], or nanoparticles of inorganic salts such as calcium phosphate [30], magnesium silicate [32], calcium sodium phosphosilicate (bioglass) [34], and clay [35].

In this work, we utilized a prodrug approach exploiting drug release after cellular uptake and entering into cytoplasm where the concentration of bio-thiols such as glutathione is almost one thousand times higher than in the blood plasma. To prepare bisphosphonate prodrug via its conjugation to HA carrier, we designed a linker that has terminals that are orthogonally reactive towards amines and thiols (Scheme 1). Starting with 1-methyl2-hydroxyethylthiol 1 and 2-thiopyridine, we synthesized 2-dithiopyridyl compound 2, following activation of the hydroxyl with di- $\mathrm{N}$-succinimidylcarbonate provided linker 3 containing 2-dithiopyridyl group on one end and $\mathrm{N}$-succinimidylcarbonate group on the other end of the linker. Drug pamidronate was then coupled to the linker through a carbamate linkage, which gave bisphosphonate derivative 4 that is amenable to further disulfide coupling with molecules carrying free thiol groups. Compound 4 was correspondingly linked to hyaluronic acid modified with thiol groups (HA-SH).

Thus, a new hyaluronan-bisphosphonate prodrug HA-//-BP with a thiol-triggered release mechanism was obtained. Previously, low molecular weight aminobisphosphonate prodrugs were prepared to be responsive to enzymatic hydrolysis of phenol carbamates [22] or cleavage of amide bond by cathepsin K [23]. Alternatively, lipophilic pivaloyloxymethyl esters of bisphosphonates were shown to be converted to active bisphosphonates by intracellular esterases [36]. In this work, a polymeric bisphosphonate prodrug activatable by biothiols in cytoplasm was prepared first. A sterically hindered disulfide bond in the middle of the releasable linker was chosen purposefully to increase the stability of the disulfide bond and ensure the drug attachment during circulation in the blood [24]. It should be noted, however, that formation of sterically hindered linear disulfide is also expected to be slower in comparison with the formation of unhindered disulfide. Despite this limitation, the successful attachment of BP to HA was confirmed by UVVis spectrophotometric observation of the generation of 2-thiopyridine side-product of 
the reaction (Figure S1) as well as by ${ }^{1} \mathrm{H}$ - and ${ }^{31} \mathrm{P}-\mathrm{NMR}$ spectroscopy (Figure S2). A characteristic peak at $2.14 \mathrm{ppm}$ corresponding to protons of methylene group adjacent to the bridging bisphosphonate carbon was observed. Another characteristic peak of methyl substituent adjacent to disulfide bond was also observed at $1.26 \mathrm{ppm}$. A peak at $4.12 \mathrm{ppm}$ was attributed to the methylene protons neighboring the carbamate oxygen atom of the linker and the rest of the protons of the linker were grouped in the region between 2.7 and $3.2 \mathrm{ppm}$ (except for the methylene protons near the carbamate $\mathrm{NH}$ group which were overlapped by HA saccharide).

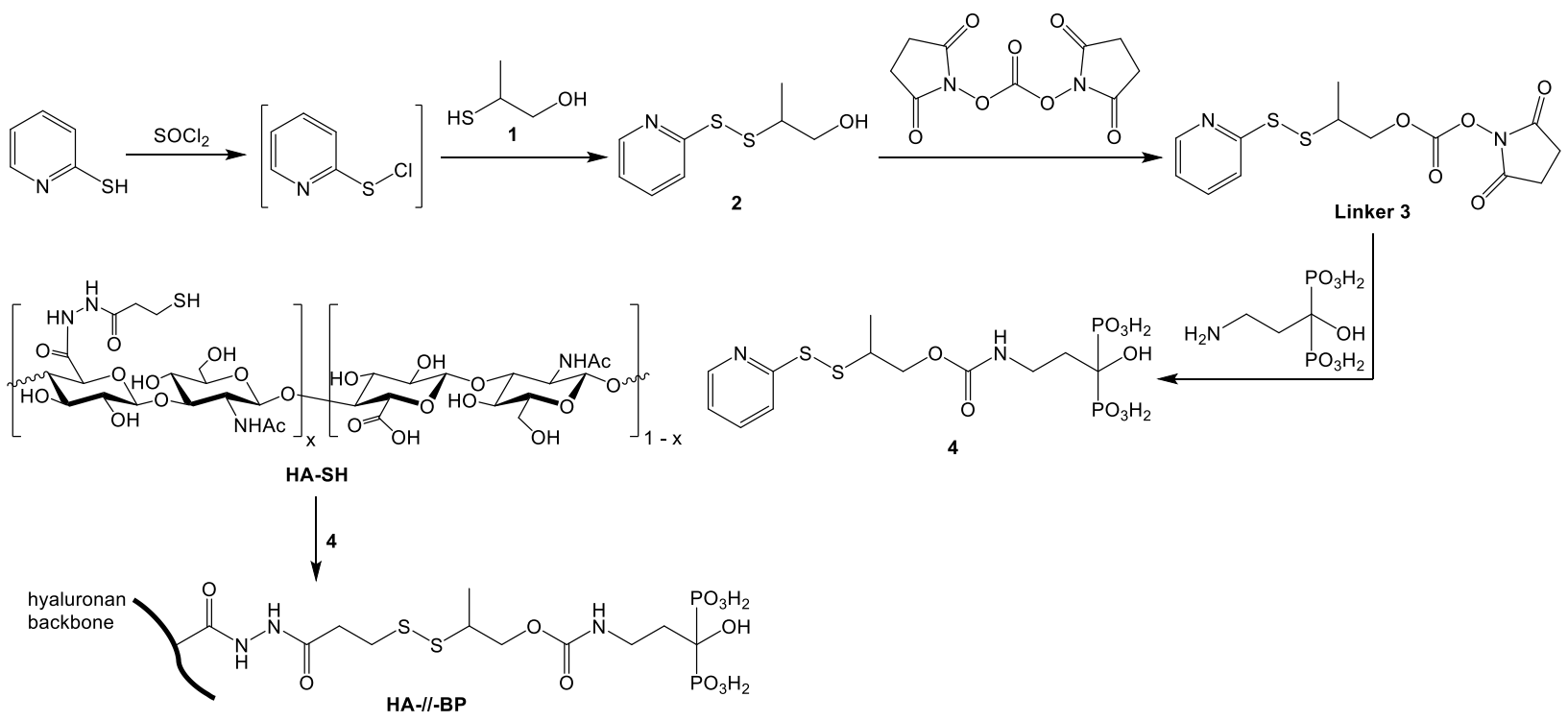

Scheme 1. Synthesis of heterobifunctional linker 3 and hyaluronan-bisphosphonate prodrug HA-//-BP with a thioltriggered release mechanism.

A self-immolative 2-methylethoxycarbonyl fragment between the disulfide bond and the amino group of pamidronate (designated as $-/ /-$ ) was designed to provide intact release of pamidronate molecules and, thus, the activation of the drug after cleavage of the disulfide bond in the cytoplasm. Previous polymer-based prodrugs exploited only glutathione-cleavable disulfanyl ethylcarbonate self-immolative side chains, which are sterically more accessible and thus should be less stable in the extracellular space $[37,38]$. Finally, we used HA polymeric material with multiple presentation of BP groups to engage them in coordination bonding to metal ions as well as to impart bone-adhesive properties to the corresponding coordination hydrogels.

\subsection{Coordination Hydrogel Formed by Releasable HA-//-BP}

Releasable HA-//-BP derivative readily formed a hydrogel upon mixing with a solution of $\mathrm{CaCl}_{2}$ (Figure 2a). HA-//-BP•Ca ${ }^{2+}$ hydrogel is an example of macromolecular network in which macromolecular chains are cross-linked through metal ions (i.e., on a molecular level). The viscoelastic properties of the hydrogel were examined in a frequency oscillation sweep experiment (Figure 2b). Moreover, an increase of strain from 1 to 300\% during the strain oscillation sweep indicated a decrease of storage $\left(G^{\prime}\right)$ modulus and an increase of loss $\left(G^{\prime \prime}\right)$ modulus starting from a strain value of $10 \%$ and reaching a crossover point at already $\sim 25 \%$ strain (Figure $2 \mathrm{c}$ ). This emphasizes the shear-thinning properties of the hydrogel. The formed hydrogel clearly displayed self-healing properties, as was judged from the time oscillation sweep experiment consisting of four cycles of alteration of strain between low (1\%) and high (300\%) values (Figure 2d). It implies that hydrogels formed by releasable $\mathrm{HA}-/ /$-BP derivative and $\mathrm{Ca}^{2+}$ ions are fully injectable and can recover their mechanical properties autonomously after injection. 


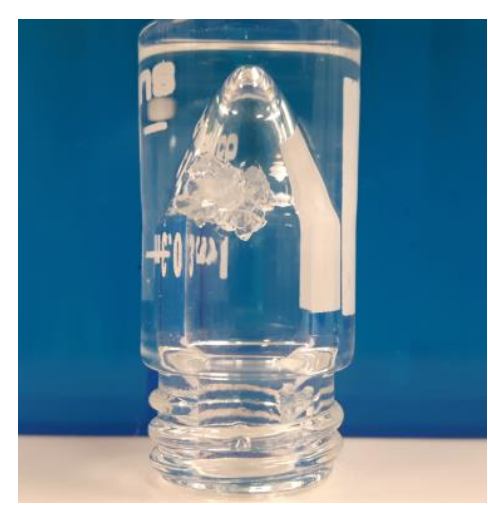

(a)

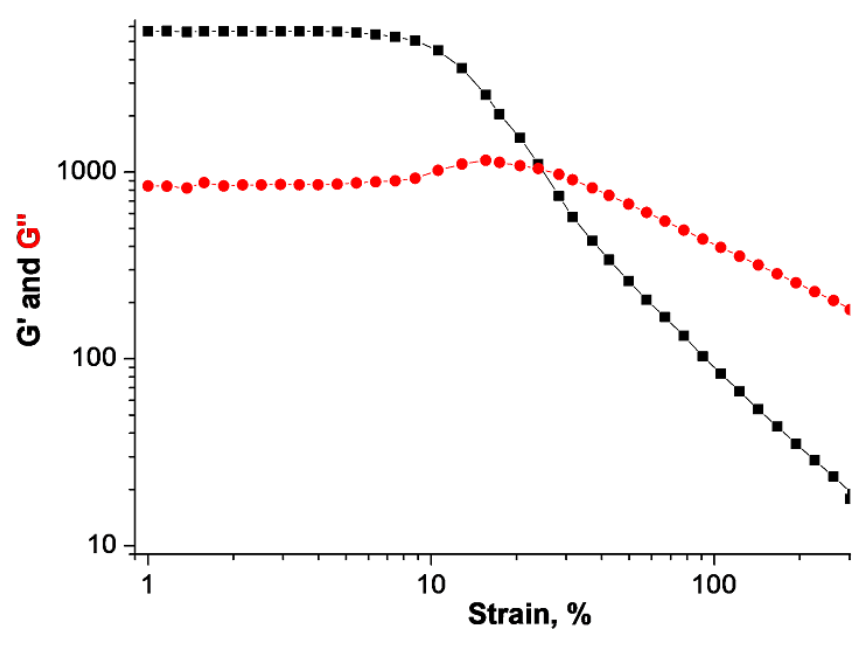

(c)

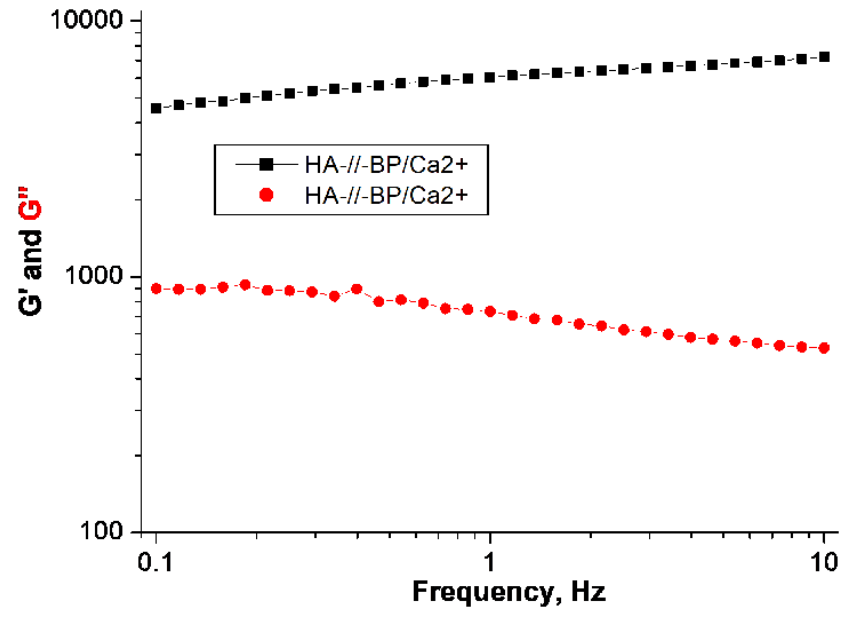

(b)

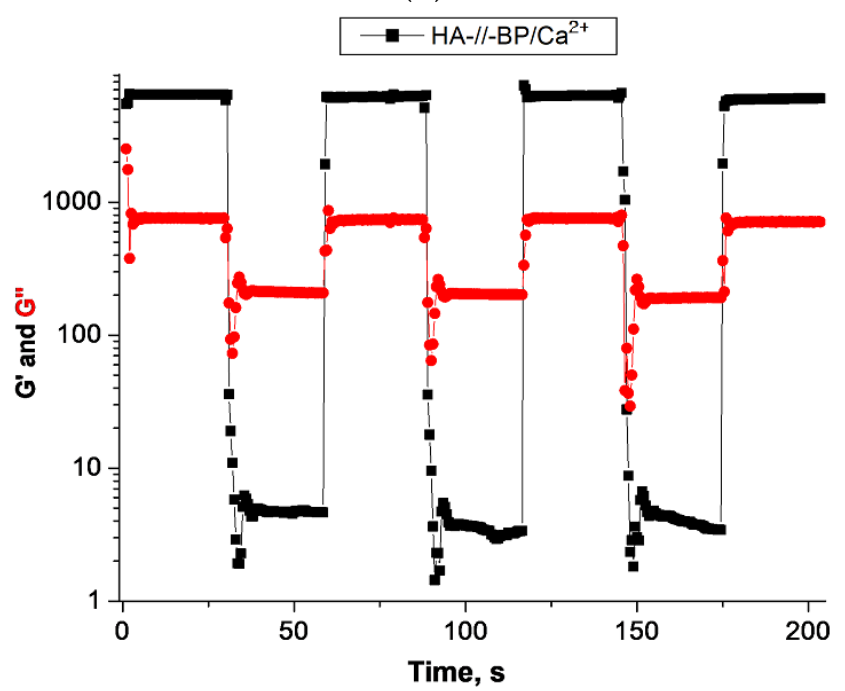

(d)

Figure 2. (a) Image of hydrogel formed by coordination cross-linking of HA-//-BP derivative by $\mathrm{Ca}^{2+}$ ions. (b) Frequency oscillation sweep of $\mathrm{HA}-/ /-\mathrm{BP} \bullet \mathrm{Ca}^{2+}$ hydrogel. (c) Strain oscillation sweep of HA-//-BP•Ca ${ }^{2+}$ hydrogel. (d) Time oscillation sweep of $\mathrm{HA}-/ /-\mathrm{BP} \bullet \mathrm{Ca}^{2+}$ hydrogel upon alteration of strain between low (1\%) and high (300\%) values. Concentrations of $\mathrm{HA}-/ /-\mathrm{BP}$ and $\mathrm{Ca}^{2+}$ ions in $\mathrm{HA}-/ /-\mathrm{BP} \bullet \mathrm{Ca}^{2+}$ hydrogel were $3 \%$ and $0.2 \mathrm{M}$, respectively.

We tested the ability of the new HA-//-BP•Ca ${ }^{2+}$ hydrogel to respond to thiols. Cleavage of disulfide bond in the linker connecting BPs with an HA backbone should result in the hydrogel dissolution and the release of any cargo molecules that are physically entrapped in the hydrogel. Moreover, such hydrogel dissolution should convert the hydrogel-linked BP prodrug into the actual bisphosphonate drug. To prove this, we incubated HA-//$\mathrm{BP} \bullet \mathrm{Ca}^{2+}$ hydrogel in $0.17 \mathrm{M} \mathrm{NaCl}$ containing $2.5 \mathrm{mM} \mathrm{CaCl} 2$ and $20 \mathrm{mM}$ dithiothreitol (DTT) at pH 7.5. The hydrogel formed by HA-//-BP derivative was almost completely decomposed after 30 min of incubation and, after $1 \mathrm{~h}$ of incubation, a white precipitate was formed in place of the hydrogel. The solid material formed upon interaction of DTT with $\mathrm{HA}-/ /-\mathrm{BP}_{\bullet} \mathrm{Ca}^{2+}$ hydrogel is the insoluble calcium pamidronate which should be generated after the detachment of pamidronate from the network. Additionally, we examined previously reported HA-BP analog [30] characterized by permanent attachment of BP groups (see structure in Figure S3 in Supplementary Materials). As expected, $\mathrm{HA}-\mathrm{BP} \bullet \mathrm{Ca}^{2+}$ hydrogel stayed intact even after 3 days of incubation with DTT. 


\subsection{Synthesis and Characterization of Releasable BP-HA-//-DN Conjugate}

To study the thiol-triggered drug release, we prepared an HA derivative in which $\mathrm{BP}$ groups were permanently attached to the HA backbone whereas another hydrophobic model amine was linked to HA via releasable linker 3. Specifically, $\mathrm{N}$-(6-aminohexyl)2,4-dinitroaniline (DN) was coupled to linker 3 via carbamate bond (Scheme 2a) and the resulting compound 5 was conjugated to HA derivative modified with BP and thiol groups (BP-HA-SH) (Scheme 2b). BP-HA-SH derivative was prepared as previously described [28] and it is characterized by permanent attachment of BP groups to the HA backbone.

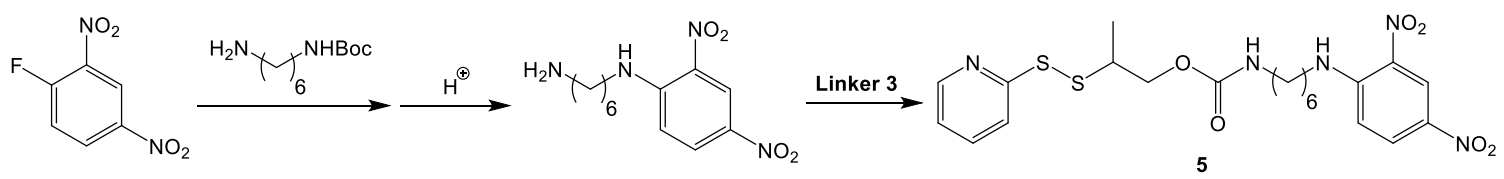

(a)

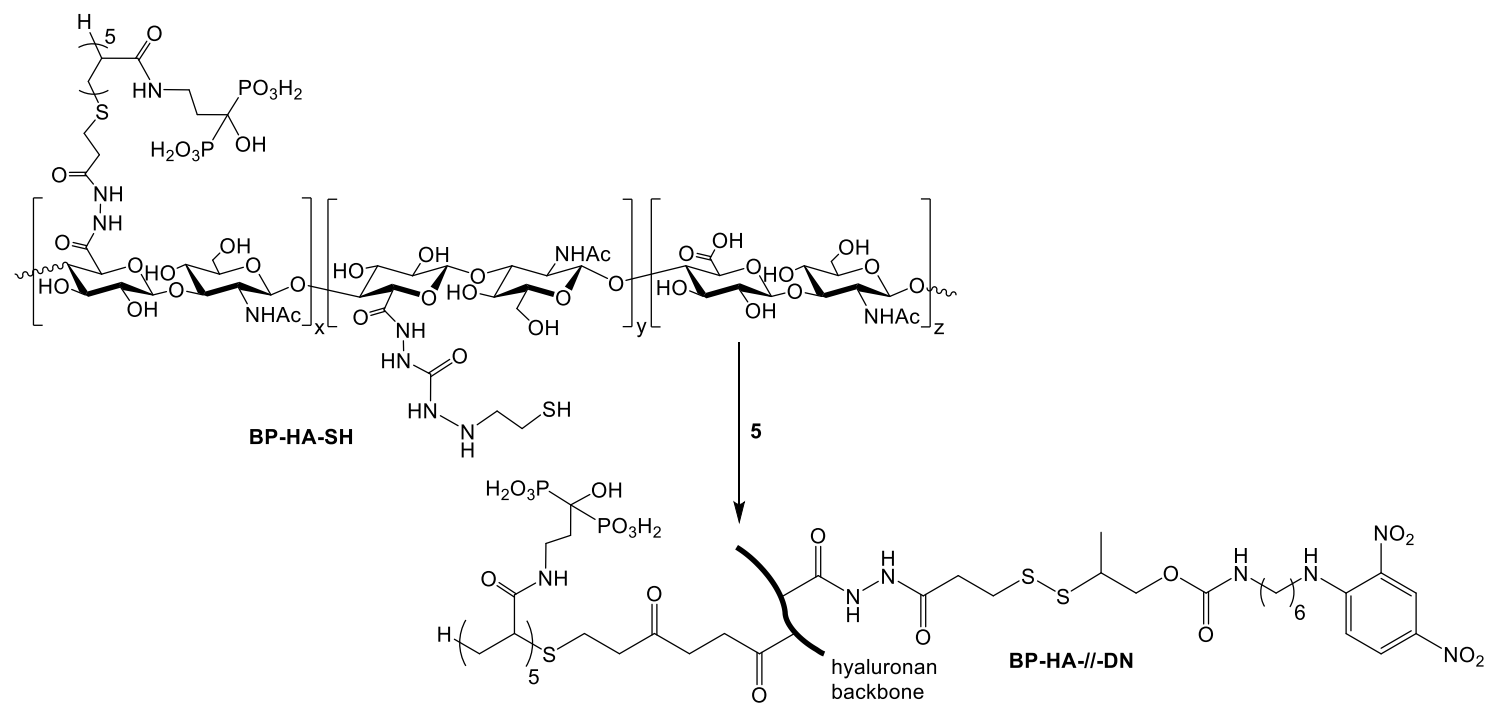

(b)

Scheme 2. (a) Synthesis of the model prodrug 5 carrying 2-dithiopyridyl groups and (b) its further conjugation to hyaluronan to obtain HA derivative with permanently attached BP groups and releasable prodrug moieties (BP-HA-//-DN).

Due to the hydrophobic properties of the attached ligand, the obtained BP-HA-//-DN derivative underwent self-association in the aqueous medium, forming nanogel particles with a hydrophobic DN core and hydrophilic HA-BP shell. The formation of nanogels was confirmed by dynamic light scattering measurements (Figure S4a). The size of the formed particles was $\sim 513 \mathrm{~nm}$. Similar nanogels formation was reported for HA dually modified with hydrophobic $5 \beta$-cholanic acid and metal ion-chelating dipicolylamine groups [39]. The size of the reported nanogels was around $225 \mathrm{~nm}$, which is less than twice the size of the newly prepared nanogels. It should be noted that the size of hydrohpobically self-assembled nanogels is dependent on many factors including the nature of appended groups, molecular weight of a backbone polymer, and the degrees of modification with the side chains.

The particles were subsequently treated with dithiothreitol (DTT) to cleave the disulfide bond between the HA backbone and hydrophobic DN moieties and, hence, to destroy the particles. According to DLS measurements, it led to the decrease of the particles size to $\sim 388 \mathrm{~nm}$ (Figure S4b) and the decrease of the particles' concentration six times (Figure S4c). These results can be rationalized by the hydrophobicity of the released DN molecules which tend to aggregate after cleavage, thus preventing the complete nanoparticles disappearance in the dispersion. 


\subsection{Thiol-Triggered Release of Covalently Linked Drugs}

In this work, we anticipated two hydrogel-based drug delivery approaches. In one approach accomplished with the HA-//-BP derivative, the cleavable linkers are placed between HA backbone and chelating BP groups (Figure 3a). The reduction of disulfide bonds in a hydrogel formed by coordination of HA-//-BP to metal ions should lead to the hydrogel dissolution and the release of physically encapsulated cargo molecules. At the same time, free aminobisphosphonate molecules are generated. In the second approach accomplished with the BP-HA-//-DN derivative, the releasable linker is placed between a biopolymer and some relevant drug ( $\mathrm{DN}$ in this case), whereas $\mathrm{BP}$ ligands are permanently conjugated to HA (Figure 3b). Therefore, thiols do not affect the corresponding coordination hydrogel, but instead trigger release of a drug from the hydrogel.

(a)

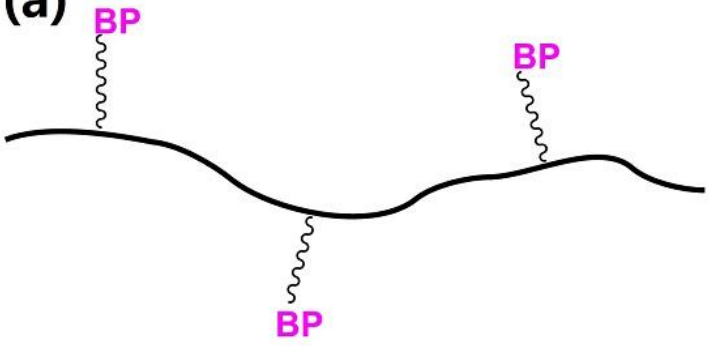

HA-//-BP (b)

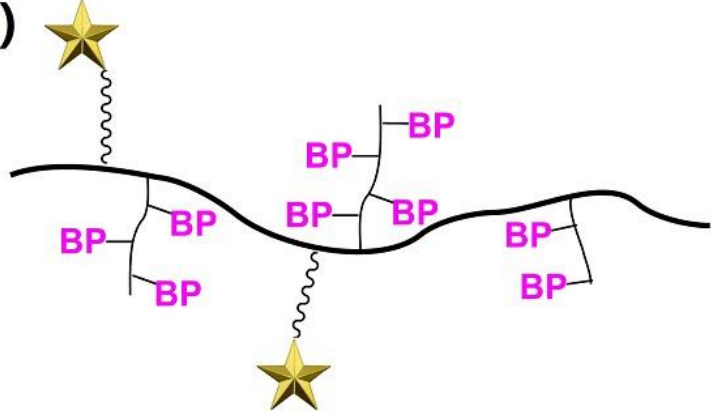

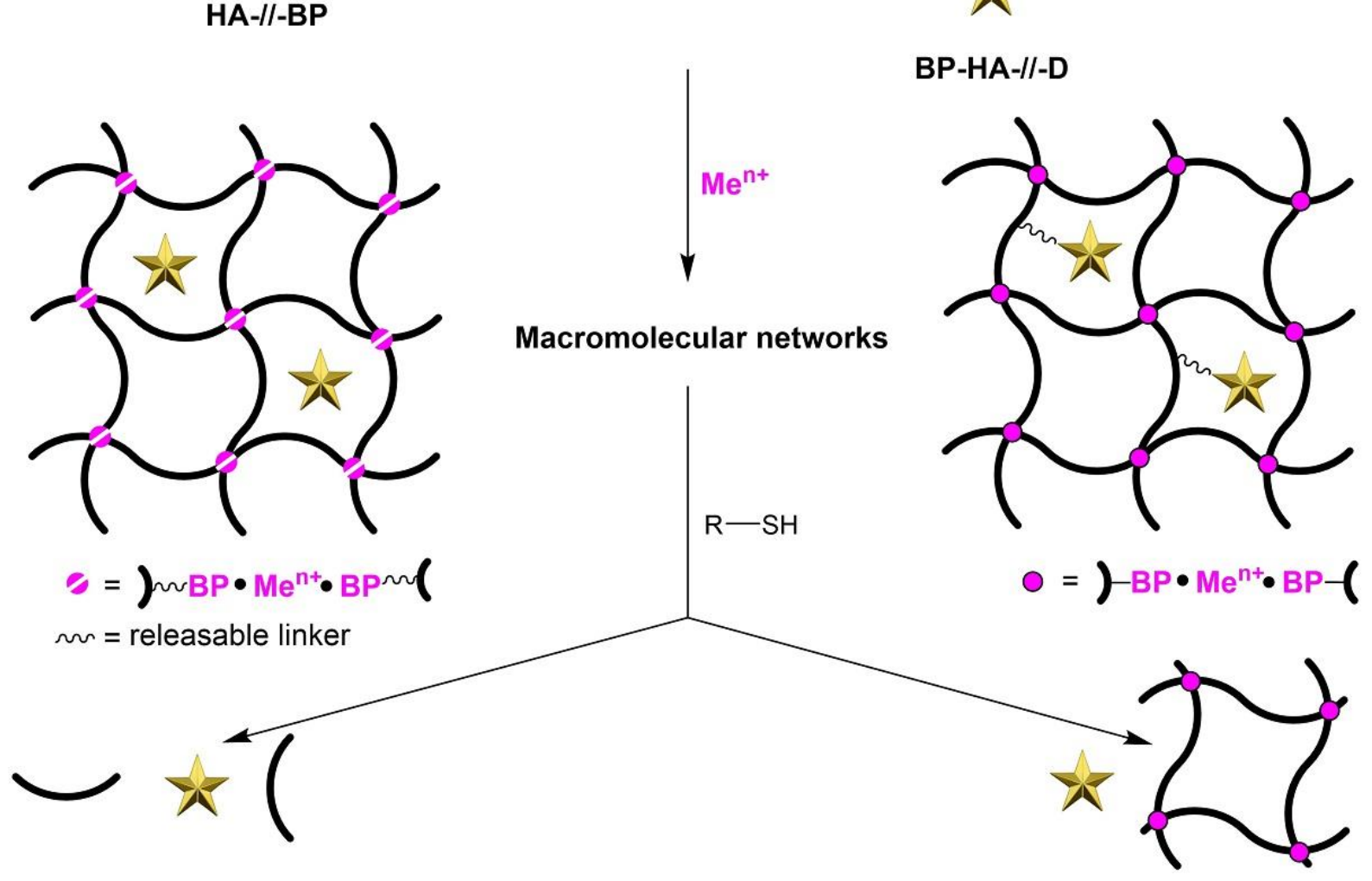

Figure 3. Two types of hyaluronan-bisphosphonate derivatives (HA-//-BP and BP-HA-//-D where D stands for a drug and -//- stands for a releasable self-immolative linker) and the respective injectable hydrogel-based drug delivery systems: (a) Intact bisphosphonate-releasing hydrogel that is decomposed upon action of thiols and (b) hydrogel-linked prodrug that releases amine-bearing drugs upon action of thiols.

The ability of the synthesized macromolecular prodrug BP-HA-//-DN to form selfhealing macromolecular or colloidal hydrogels was subsequently evaluated. The hydrogels were readily formed, and they were both characterized by self-healing properties (Figure S5). The $\mathrm{Ca}^{2+} \bullet \mathrm{BP}-\mathrm{HA}-/ /$-DN hydrogel was subsequently incubated in an aqueous 
buffer at $\mathrm{pH}$ 7.4. Alternatively, the incubation was performed in the buffer containing $20 \mathrm{mM}$ dithiothreitol (DTT). The results of the release studies are shown in Figure 4. We observed almost no release of the model DN drug under non-reducing conditions. However, the addition of DTT initiated the release of DN which occurred almost at a constant rate between the second and fifth day. After six days, the release was gradually diminished.

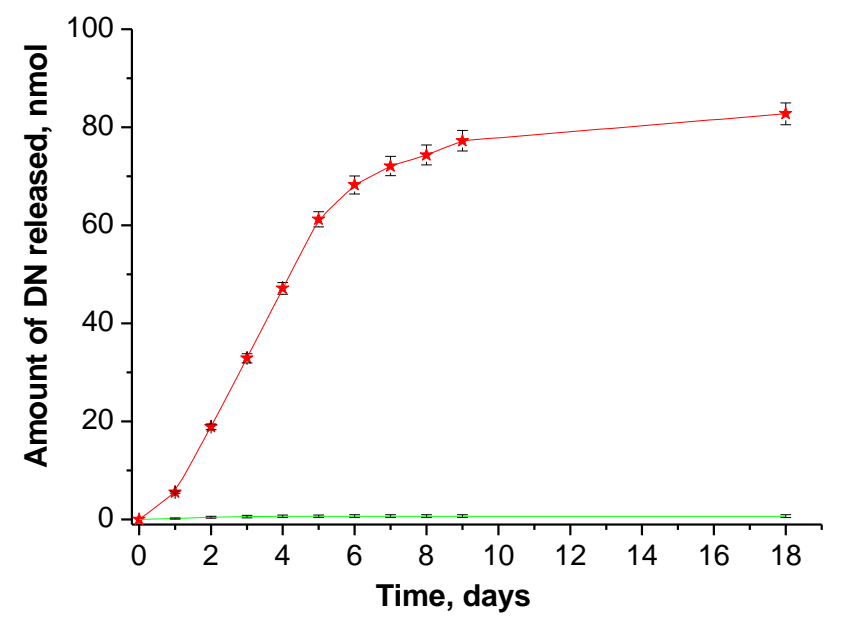

(a)

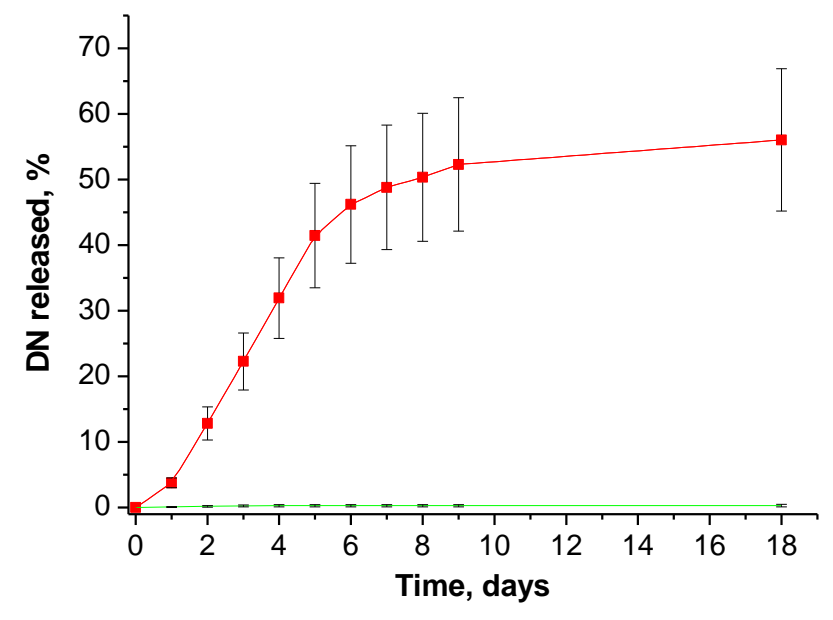

(b)

Figure 4. (a) Absolute amount and (b) percentage of $N$-(6-aminohexyl)-2,4-dinitroaniline (DN) released from Ca ${ }^{2+} \bullet \mathrm{BP}^{-\mathrm{HA}-}$ //-DN hydrogel upon incubation in $0.17 \mathrm{M} \mathrm{NaCl}$ containing $2.5 \mathrm{mM} \mathrm{CaCl}_{2}$ (pH 7.4). The red curve corresponds to the release when $20 \mathrm{mM}$ DTT was present in the incubation medium. The green curve corresponds to the release when no DTT was present in the release medium.

To the best of our knowledge, the demonstrated model drug release from HA hydrogel is the first study of a hydrogel-linked prodrug approach which exploits the thiol-disulfide exchange reaction in the interior of a macroscopic hydrogel. Mainly, disulfide bonds were introduced as part of cross-linkages between polymeric chains [40], thus enabling the thioltriggered release of encapsulated molecules or cells through the hydrogel's dissolution (as exemplified also in Figure 3a). The use of disulfide bonds as side linkages of differently cross-linked networks was so far utilized only for demonstration of modular "catch and release" from a hydrogel surface [41].

\subsection{Synthesis of DN-hyd-HA-//-BP Conjugate with Dual Release Mechanism}

For the delivery of aminobisphosphonates and physically encapsulated hydrophobic simvastatin, we anticipated the orthogonal conjugation of hydrophilic BP and hydrophobic DN ligands through differentially cleavable linkers. Specifically, we sought to achieve hydrolytic cleavage of DN ligands under acidic conditions while initiating the release of BP drugs in the reducing microenvironment of cytoplasm. Release under slightly acidic conditions was rationalized by two reasons. Thus, tumor microenvironments are characterized by slightly acidic $\mathrm{pH}$ (around 6.8), as well as bone resorption occurs because of the acidic dissolution of calcium phosphate mineral. On the other hand, the uptake of the HA-based nanogels by HA receptor-mediated endocytosis should bring them into endosomes and later to lysosomes, which are characterized by microenvironments with gradually decreasing $\mathrm{pH}$ from 6.8 to 5 .

Based on the above considerations, DN-hyd-HA-//-BP derivative (hyd denotes hydrazone linkage, whereas -//- denotes self-immolative disulfide linkage) was prepared starting from hyaluronic acid modified with hydrazide and thiol groups (hy-HA-SH) (Scheme 3a). Dually modified HA was first treated with BP reagent 4 for $24 \mathrm{~h}$ in an aque- 
ous solution at $\mathrm{pH} 7.5$ providing the intermediate hy-HA-//-BP carrying hydrazide and BP groups.<smiles>O=Cc1ccc(C(=O)ON2C(=O)CCC2=O)cc1</smiles>

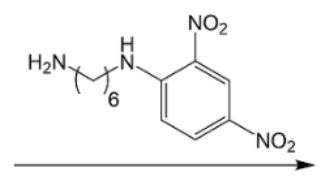<smiles>O=Cc1ccc(C(=O)NCNC(=O)c2ccc([N+](=O)[O-])cc2[N+](=O)[O-])cc1</smiles>

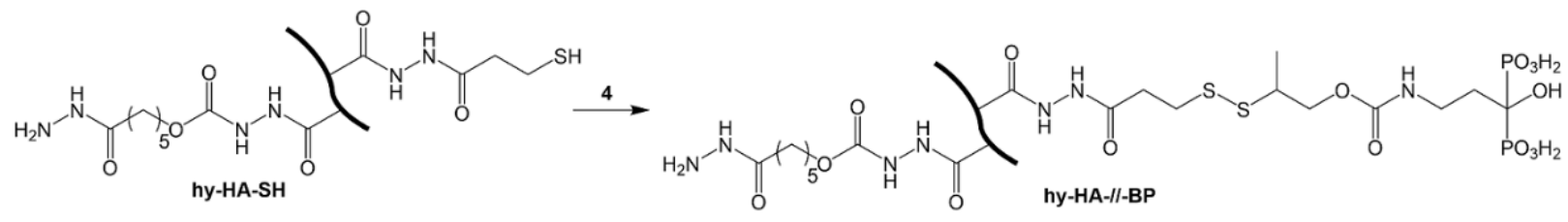

(b)

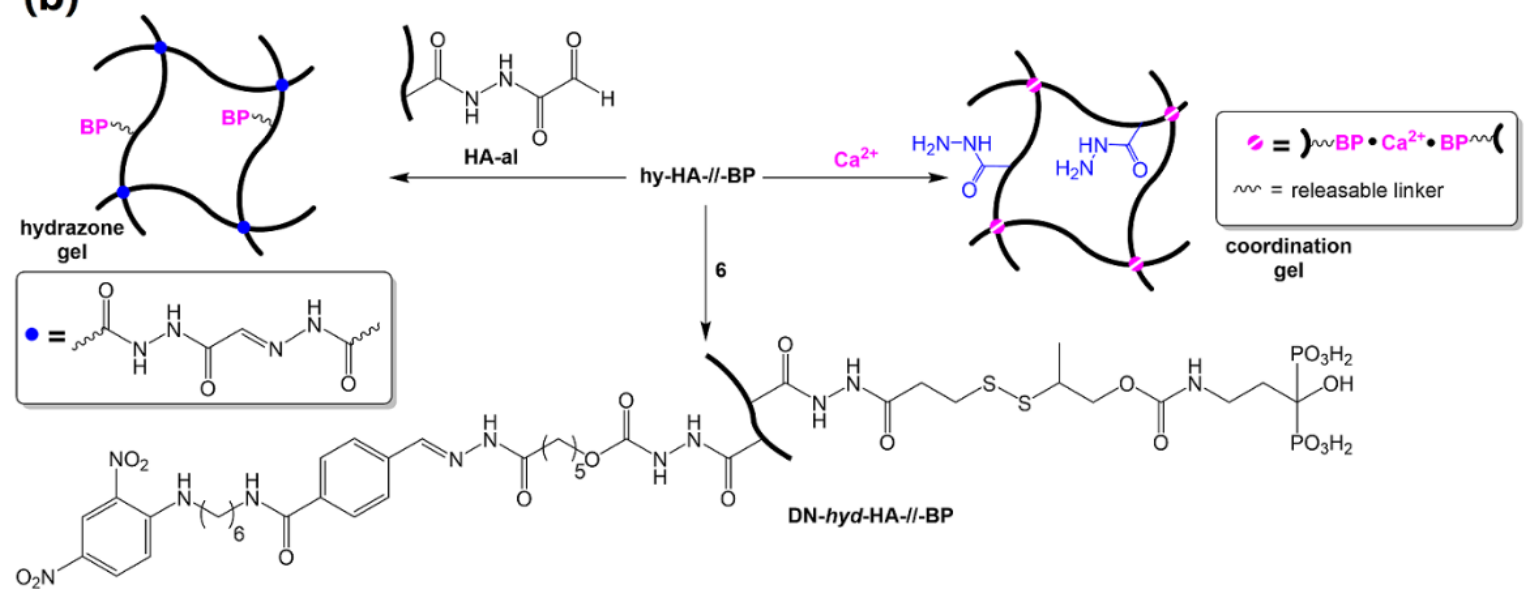

Scheme 3. (a) Synthesis of aldehyde-modified DN derivative and hyaluronic acid bearing hydrazide and releasable BP groups (hy-HA-//-BP). (b) Use of hy-HA-//-BP derivative for the preparation of hydrazone and coordination hydrogels as well as for generation of amphiphilic HA derivative bearing hydrophobic DN and hydrophilic BP groups (DN-hyd-HA-//-BP).

The functionality of the hydrazide and BP groups in hy-HA-//-BP was verified by gel tests. Particularly, hydrazone cross-linked and coordination hydrogels were successfully formed upon the mixing of hy-HA-//-BP with aldehyde-modified $\mathrm{HA}$ (HA-al) and $\mathrm{CaCl}_{2}$ solutions (Scheme $3 b$ ). The treatment of hy-HA-//-BP with aldehyde-modified DN derivative 6 was subsequently performed in a mixture of water and DMSO $(1: 3, v / v)$ at $\mathrm{pH} 5$ for $24 \mathrm{~h}$. The excess of unreacted 6 was removed by repeated dialysis of the reaction mixture against DMSO which was verified by UV-Vis spectroscopy (Figure S6). Final dialysis against water provided self-assembly of the amphiphilic DN-hyd-HA-//-BP derivative (Scheme $3 b$ ) which was verified by DLS analysis (Figure S7a).

The obtained DN-hyd-HA-//-BP was characterized by ${ }^{1} \mathrm{H}-\mathrm{NMR}$ spectroscopy (Figure 5). Aromatic protons of 2,4-dinitroaniline and phenylene moieties were observed at 8.7, 8.0, 7.5 , and $6.8 \mathrm{ppm}$. It confirmed the hydrazone coupling of reagent 6 to hy-HA-//-BP. The successful disulfide attachment of BP derivative 4 was evident from the appearance of the peak of methyl substituent of 4 at $1.2 \mathrm{ppm}$. Other peaks corresponding to methylene groups of the precursor compounds 4 and 6 (designated in Figure 5 as 1, 2, 4, and 5-13) were also identified in the spectrum. 


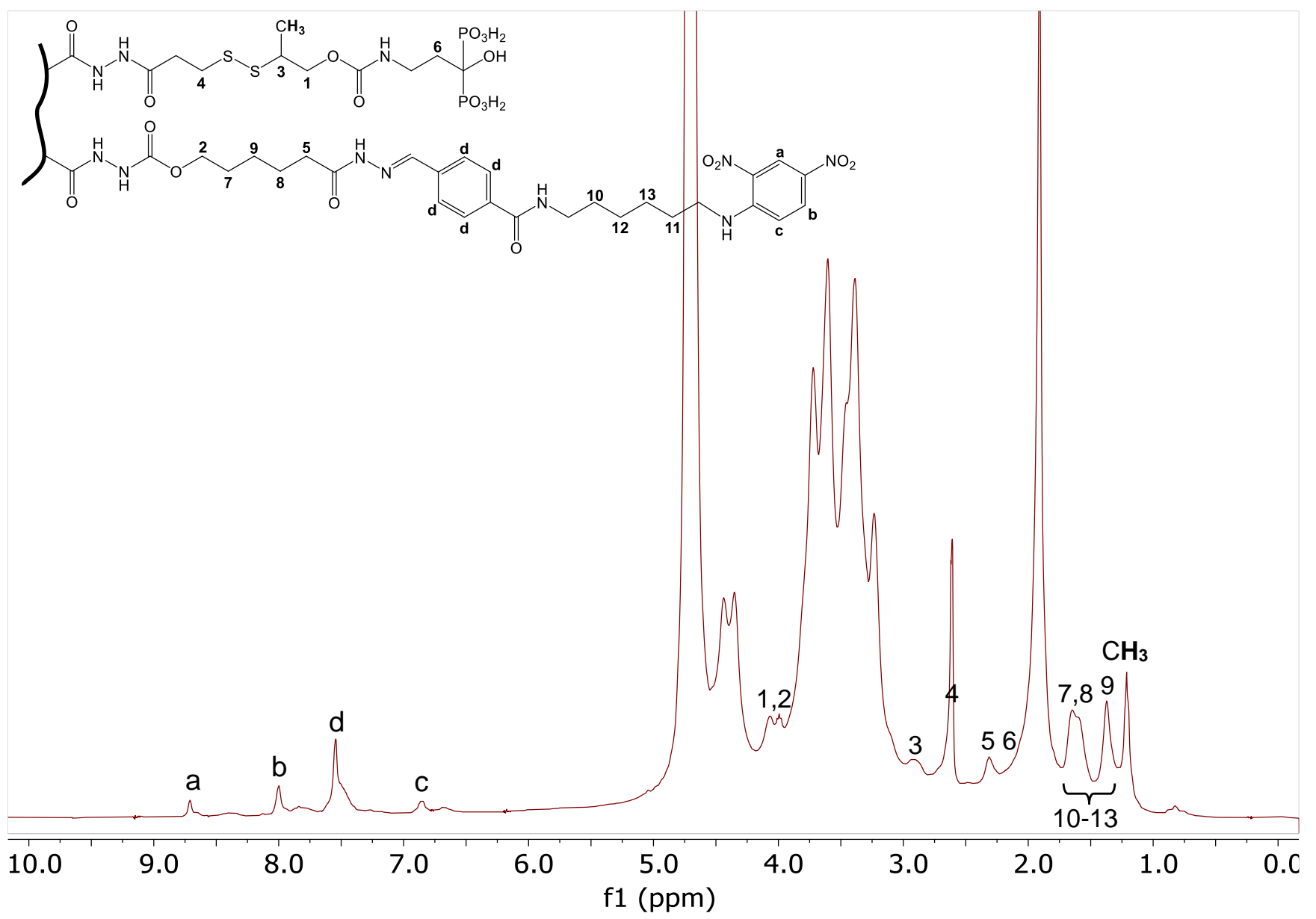

Figure 5. ${ }^{1} \mathrm{H}-\mathrm{NMR}$ spectrum of DN-hyd-HA-//-BP derivative.

To evaluate the possibility of acidic release of physically loaded cargos, we encapsulated simvastatin (SIM) in DN-hyd-HA-//-BP nanogels. Simvastatin was added to DN-hyd-HA-//-BP in DMSO and subsequently dialyzed against water to permit homogeneous encapsulation of SIM in DN-hyd-HA-//-BP nanogels. Dialysis of the mixture against water provided substitution of DMSO to water and the entrapment of SIM in the hydrophobic pocket formed by the self-assembled DN moieties. The hydrodynamic diameter of SIM loaded nanogels was not altered much in comparison with the unloaded DN-hyd-HA-//-BP nanogels, as was verified from DLS measurements (Figure S7b). The SIM encapsulation efficiency was estimated by UV-Vis spectroscopy and found to be $55 \mu \mathrm{g} / \mathrm{mg}$ of SIM@DN-hyd-HA-//-BP, which corresponded to a loading efficiency of $47.3 \%$. This loading efficiency was four times higher than the reported encapsulation of SIM in HA nanogels prepared by disulfide cross-linking of 11-amino-1-undecanethiol hydrophobic side chains attached to the HA backbone [42].

\subsection{Acid-Triggered Release of DN Imaging Groups and Physically Encapsulated Simvastatin}

The $\mathrm{pH}$-controlled release of DN reagent 6 from SIM@DN-hyd-HA-//-BP was investigated (Figure 6a). As expected, the detachment of hydrophobic DN moieties was accompanied by the release of the physically encapsulated SIM (Figure 6b). This result was expected because the acidic hydrolysis of the hydrazone bond between hydrophobic $\mathrm{DN}$ residues and hydrophilic HA backbone should disassemble the nanogel particles. The release of both 6 and SIM occurred largely during the first two days, but with much less burst effect than is normally observed from hydrogels physically loaded with SIM [43]. We noticed that the release of SIM was diminished in comparison with the release of 6 . HPLC analysis revealed that SIM is substantially more hydrophobic than 6 , which anticipates less 
solubility of SIM in the aqueous media. SIM can be effectively dispersed in water when entrapped in DN-hyd-HA-//-BP nanogels. However, disassembly of the nanogels should also be accompanied by aggregation/precipitation of SIM.

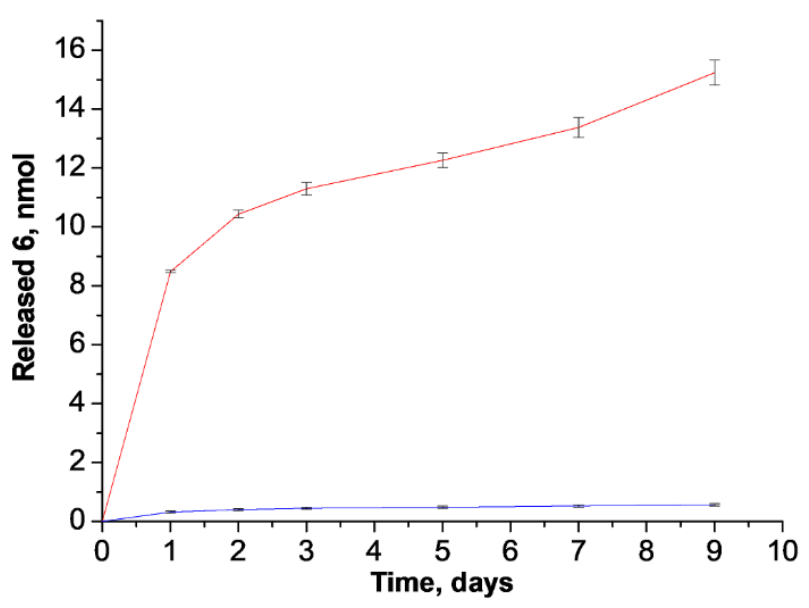

(a)

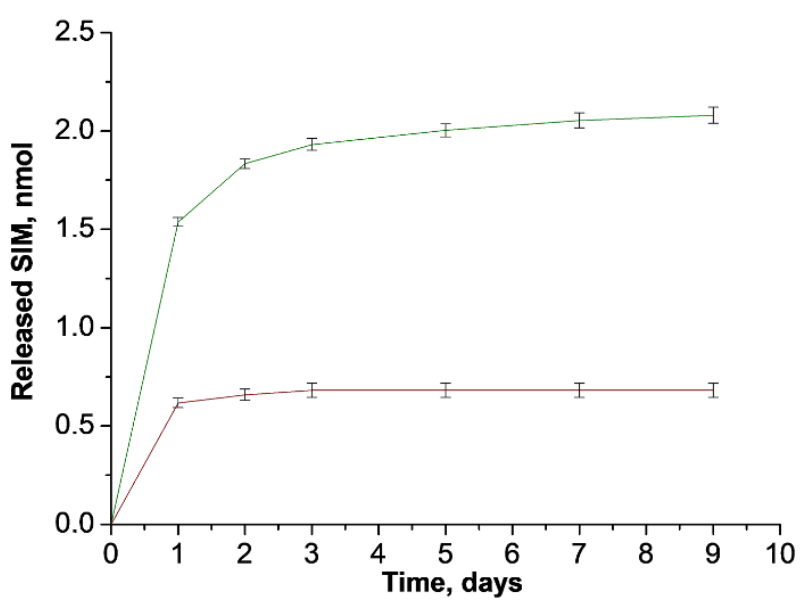

(b)

Figure 6. (a) Amount of DN derivative 6 released upon incubation of SIM@DN-hyd-HA-//-BP in either 0.1 M NaOAc/ AcOH $\mathrm{pH}=5.0$ buffer (red curve) or $1 \times \mathrm{PBS}$ buffer $\mathrm{pH}=7.4$ (blue curve). (b) Amount of simvastatin (SIM) released upon incubation of SIM@DN-hyd-HA-//-BP in either 0.1 M NaOAc/AcOH pH = 7.4 buffer (green curve) or $1 \times$ PBS buffer $\mathrm{pH}=7.4$ (brown curve).

Essentially, the release of SIM from nanogels particles becomes halted due to the transformation of the system of homogeneously dispersed nanogels into a heterogeneous two-phase system. This limitation of the present in vitro system might be overcoming by concerted hydrolytic and enzymatic HA degradation in vivo. Nonetheless, the current in vitro model demonstrates that the release of SIM is pH-controlled if the drug is hydrophobically encapsulated in an amphiphilic conjugate in which hydrophobic and hydrophilic parts are linked through a hydrazone bond.

The prepared DN-hyd-HA-//-BP derivative is multifunctional because it can form both bulk self-healing hydrogels and nanogels, depending on the functionalized biopolymer concentration. These different hydrogel formulations can be used interchangeably as localized drug depots and for the systemic delivery of drugs, respectively. Importantly, the developed hydrogel system is made multi-responsive by the combination of orthogonally cleavable linkers for the network-linked prodrug construction and for the attachment of moieties that enable hydrophobic encapsulation through self-association. In particular, the DN-hyd-HA-//-BP derivative enables the immobilization of hydrophilic aminobisphosphonates and hydrophobic simvastatin with their subsequent orthogonal and intact release upon the action of bio-thiols and acids, respectively.

\section{Conclusions}

In summary, we utilized different compartments of bisphosphonate-decorated nanogel particles and different types of labile chemical bonds to achieve the orthogonal release of pamidronate and simvastatin characterized by opposing solubility in aqueous media. Aminobisphosphonate pamidronate was conjugated to hyaluronic acid through a self-immolative disulfide linker, whereas hydrophobic imaging ligand (DN) was linked through an acid-labile hydrazone bond. The resulting amphiphilic DN-hyd-HA-//-BP conjugate was self-assembled into nanogel particles in aqueous media. We demonstrated that hydrophobic simvastatin can be physically entrapped in DN-hyd-HA-//-BP and subsequently released under acidic conditions, which was attributed to the hydrolysis of the hydrazone bond between DN residues and HA backbone. When DN residues were linked through the disulfide bond, as in the BP-HA-//-DN derivative, orthogonal cleavage under 
reducing conditions was observed. Moreover, various chemical attachments of BP ligands to HA biopolymer provided the possibility to form self-healing macroscopic hydrogels that deliver drugs either through stimuli-responsive hydrogel dissolution or chemical detachment from the network. This simple and modular approach provides injectable hydrogel depots which can release drugs locally in bone resorption sites. Alternatively, the prepared nanogels are potential candidates to deliver antiresorptive/anti-cancer and bone growth inducing drugs systemically to osteoporosis sites.

Supplementary Materials: The following are available online at https: / www.mdpi.com/article / $10.3390 /$ polym13132106/s1. Figure S1: UV-Vis characterization of the reaction of conjugation of bisphosphonate reagent 4 to thiolated HA (HA-SH); Figure S2: ${ }^{1} \mathrm{H}$ - and ${ }^{31} \mathrm{P}-\mathrm{NMR}$ spectra for releasable HA-/ /-BP conjugate; Figure S3: Chemical structure of HA-BP derivative; Figure S4: (a) DLS of BP-HA-//-DN solution in water $(0.125 \mathrm{mg} / \mathrm{mL})(\mathbf{b})$ DLS of aqueous solution of BP-HA//-DN treated with $30 \mathrm{mM}$ DTT. (c) Diagram of particles concentration as a function of particles size; Figure S5: (a) Frequency oscillation sweep of $\mathrm{Ca}^{2+} \bullet \mathrm{BP}-\mathrm{HA}-/ /-\mathrm{DN}$ hydrogel. (b) Frequency oscillation sweep of $\mathrm{Ca}^{2+} \bullet \mathrm{BP}-\mathrm{HA}-/ /$-DN hydrogel. (c) Time oscillation sweep of $\mathrm{Ca}^{2+} \bullet \mathrm{BP}-\mathrm{HA}-/ /$ $\mathrm{DN}$; Figure S6: UV-Vis analysis of DMSO media used for the dialysis of reaction mixture of hydrazone coupling of 6 to hy-HA-//-BP derivative; Figure S7: (a) DLS of DN-hyd-HA-//-BP solution in water $(0.5 \mathrm{mg} / \mathrm{mL})$ and (b) DLS of SIM@DN-hyd-HA-//-BP solution in water $(0.5 \mathrm{mg} / \mathrm{mL})$.

Author Contributions: Conceptualization, methodology, investigation, writing, D.A.O.; formal analysis, M.L.; resources, supervision, M.M. All authors have read and agreed to the published version of the manuscript.

Funding: This research was funded by the Swedish Research Council, grant number 2017-04651.

Institutional Review Board Statement: Not applicable.

Informed Consent Statement: Not applicable.

Data Availability Statement: All of the data are displayed in the article.

Acknowledgments: The authors would like to thank Padryk Merkl of Karolinska Institutet, Department of Microbiology, Tumor and Cell Biology for technical support.

Conflicts of Interest: The authors declare no conflict of interest. The funders had no role in the design of the study; in the collection, analyses, or interpretation of data; in the writing of the manuscript; or in the decision to publish the results.

\section{References}

1. Coleman, R.E. Skeletal complications of malignancy. Cancer 1997, 80, 1588-1594. [CrossRef]

2. Goltzman, D. Osteolysis and cancer. J. Clin. Investig. 2001, 107, 1219-1220. [CrossRef]

3. Piperno-Neumann, S.; Le Deley, M.-C.; Redini, F.; Pacquement, H.; Marec-Bérard, P.; Petit, P.; Brisse, H.; Lervat, C.; Gentet, J.C.; Entz-Werlé, N.M.; et al. Zoledronate in combination with chemotherapy and surgery to treat osteosarcoma (OS2006): A randomised, multicentre, open-label, phase 3 trial. Lancet Oncol. 2016, 17, 1070-1080. [CrossRef]

4. Tu, K.N.; Lie, J.D.; Wan, C.K.V.; Cameron, M.; Austel, A.G.; Nguyen, J.K.; Van, K.; Hyun, D. Osteoporosis: A Review of Treatment options. Pharm. Ther. 2018, 43, 92-104.

5. Rosen, C.J.; Bilezikian, J.P. Anabolic Therapy for Osteoporosis. J. Clin. Endocrinol. Metab. 2001, 86, 957-964. [CrossRef] [PubMed]

6. Leder, B.Z. Optimizing Sequential and Combined Anabolic and Antiresorptive Osteoporosis Therapy. J. Bone Miner. Res. 2018, 2, 62-68. [CrossRef] [PubMed]

7. Abourehab, M.A.S. Hyaluronic Acid Modified Risedronate and Teriparatide Co-loaded Nanocarriers for Improved Osteogenic Differentiation of Osteoblasts for the Treatment of Osteoporosis. Curr. Pharm. Des. 2019, 25, 2975-2988. [CrossRef] [PubMed]

8. Dong, J.; Tao, L.; Abourehab, M.A.S.; Hussain, Z. Design and development of novel hyaluronate-modified nanoparticles for combo-delivery of curcumin and alendronate: Fabrication, characterization, and cellular and molecular evidences of enhanced bone regeneration. Int. J. Biol. Macromol. 2018, 116, 1268-1281. [CrossRef]

9. Li, J.; Mooney, D.J. Designing hydrogels for controlled drug delivery. Nat. Rev. Mater. 2016, 1, 16071. [CrossRef]

10. Imitaz, N.; Niazi, M.B.K.; Fasim, F.; Khan, B.A.; Bano, S.A.; Shah, G.M.; Badshah, M.; Menaa, F.; Uzair, B. Fabrication of an Original Transparent PVA/Gelatin Hydrogel: In Vitro Antimicrobial Activity against Skin Pathogens. Int. J. Polym. Sci. 2019. [CrossRef] 
11. Khan, B.A.; Ullah, S.; Khan, M.K.; Uzair, B.; Menaa, F.; Braga, V.A. Fabrication, Physical Characterization, and In Vitro, In Vivo Evaluation of Ginger Extract-Loaded Gelatin/Poly(Vinyl Alcohol) Hydrogel Films Against Burn Wound Healing in Animal Model. AAPS Pharm. Sci. Tech. 2020, 21, 323. [CrossRef]

12. Russel, R.G.G. Bisphosphonates: The first 40 years. Bone 2011, 49, 2-19. [CrossRef] [PubMed]

13. Mundy, G.; Garrett, R.; Harris, S.; Chan, J.; Chen, D.; Rossini, G.; Boyce, B.; Zhao, M.; Gutierrez, G. Stimulation of bone formation in vitro and in rodents by statins. Science 1999, 286, 1946-1949. [CrossRef] [PubMed]

14. Edwards, C.J.; Hart, D.J.; Spector, T.D. Oral statins and increased bone mineral density in postmenopausal women. Lancet 2000, 355, 2218-2219. [CrossRef]

15. Dai, L.; Xu, M.; Wu, H.; Xue, L.; Yuan, D.; Wang, Y.; Shen, Z.; Zhao, H.; Hu, M. The functional mechanism of simvastatin in experimental osteoporosis. J. Bone Miner. Metab. 2016, 34, 23-32. [CrossRef] [PubMed]

16. Tikiz, C.; Tikiz, H.; Taneli, F.; Gümüşer, G.; Tüzün, Ç. Effects of simvastatin on bone mineral density and remodeling parameters in postmenopausal osteopenic subjects: 1-year follow-up study. Clin. Rheumatol. 2005, 24, 447-452. [CrossRef]

17. Young, R.N.; Grynpas, M.D. Targeting therapeutics to bone by conjugation with bisphosphonates. Curr. Opin. Pharmacol. 2018, 40, 87-94. [CrossRef]

18. Vasvani, S.; Kulkarni, P.; Rawtani, D. Hyaluronic acid: A review on its biology, aspects of drug delivery, route of administration and a special emphasis on its approved marketed products and recent clinical studies. Int. J. Biol. Macromol. 2020, 151, 1012-1029. [CrossRef]

19. Bayer, I.S. Hyaluronic Acid and Controlled Release: A Review. Molecules 2020, 256, 2649. [CrossRef]

20. Menaa, F.; Menaa, A.; Menaa, B. Hyaluronic Acid and Derivatives for Tissue Engineering. J. Biotechnol. Biomater. 2011, S3. [CrossRef]

21. Lee, S.Y.; Kang, M.S.; Jeong, W.Y.; Han, D.-W.; Kim, K.S. Hyaluronic Acid-Based Theranostic Nanomedicines for Targeted Cancer Therapy. Cancers 2020, 12, 940. [CrossRef]

22. Chen, G.; Arns, S.; Young, R.N. Determination of the Rat in Vivo Pharmacokinetic profile of a Bone-Targeting Dual-Action Pro-Drug for Treatment of Osteoporosis. Bioconjugate Chem. 2015, 26, 1095-1103. [CrossRef] [PubMed]

23. Xie, H.; Chen, G.; Young, R.N. Design, Synthesis, and Pharmacokinetics of a Bone-Targeting Dual-Action prodrug for the Treatment of Osteoporosis. J. Med. Chem. 2017, 60, 7012-7028. [CrossRef]

24. Pillow, T.H.; Sadowski, J.D.; Zhang, D.P.; Shang-Fan, Y.; Del Rosario, G.; Xu, K.; Xe, J.; Bhakta, S.; Ohri, R.; Kozak, K.R.; et al. Decoupling of stability and release in disulfide bonds with antibody-small molecule conjugates. Chem. Sci. 2017, 8, 366-370. [CrossRef]

25. Morpurgo, M.; Bayer, E.A.; Wilchek, M. N-Hydroxysuccinimide carbonates and carbamates are useful reactive reagents for coupling ligands to lysines on proteins. J. Biochem. Biophys. Methods 1999, 38, 17-28. [CrossRef]

26. Ossipov, D.A.; Kootala, S.; Yi, Z.; Yang, X.; Hilborn, J. Orthogonal Chemoselective Assembly of Hyaluronic Acid Networks and Nanogels for Drug Delivery. Macromolecules 2013, 46, 4105-4113. [CrossRef]

27. Ossipov, D.A.; Yang, X.; Varghese, O.P.; Kootala, S.; Hilborn, J. Modular approach to functional hyaluronic acid hydrogels using orthogonal chemical reactions. Chem. Commun. 2010, 46, 8368-8370. [CrossRef]

28. Kootala, S.; Zhang, Y.; Ghalib, S.; Tolmachev, V.; Hilborn, J.; Ossipov, D.A. Control of Growth Factor Binding and Release in Bisphosphonate Functionalized Hydrogels Guides Rapid Differentiation of Precursor Cells In Vitro. Biomater. Sci. 2016, 4, 250-254. [CrossRef] [PubMed]

29. Varghese, O.P.; Sun, W.; Hilborn, J.; Ossipov, D. In situ Cross-Linkable High Molecular Weight Hyaluronan-Bisphosphonate Conjugate for Localized Delivery and Cell-Specific Targeting: A Hydrogel Linked Prodrug Approach. J. Am. Chem. Soc. 2009, 131, 8781-8783. [CrossRef] [PubMed]

30. Nejadnik, M.R.; Yang, X.; Bongio, M.; Alghamdi, H.; van den Beucken, J.; Huysmans, M.; Jansen, J.; Hilborn, J.; Ossipov, D.; Leeuwenburgh, S.C.G. Self-healing Hybrid Nanocomposites Consisting of Biosphosphonated Hyaluronan and Calcium Phosphate Nanoparticles. Biomaterials 2014, 35, 6918-6929. [CrossRef]

31. Shi, L.; Carstensen, H.; Hölzl, K.; Lunzer, M.; Li, H.; Hilborn, J.; Ovsianikov, A.; Ossipov, D. Dynamic Coordination Chemistry Enables Free Directional Printing of Biopolymer Hydrogel. Chem. Mater. 2017, 29, 5816-5823. [CrossRef]

32. Shi, L.; Han, Y.; Hilborn, J.; Ossipov, D. "Smart" drug loaded nanoparticle delivery from a self-healing hydrogel enabled by dynamic magnesium-biopolymer chemistry. Chem. Commun. 2016, 52, 11151-11154. [CrossRef] [PubMed]

33. Shi, L.; Zhao, Y.; Xie, Q.; Fan, C.; Hilborn, J.; Dai, J.; Ossipov, D. Moldable Hyaluronan Hydrogel Enabled by Dynamic Metal-Bisphosphonate Coordination Chemistry for Wound Healing. Adv. Healthc. Mater. 2018, 7. [CrossRef] [PubMed]

34. Diba, M.; An, J.; Schmidt, S.; Hembury, M.; Ossipov, D.; Boccaccini, A.R.; Leeuwenburgh, S.C.G. Exploiting BisphosphonateBioactive Glass Interactions for the Development of Self-Healing and Bioactive Composite Hydrogels. Macromol. Rapid Commun. 2016, 37, 1952-1959. [CrossRef] [PubMed]

35. Kim, Y.-H.; Yang, X.; Shi, L.; Lanham, S.; Hilborn, J.; Oreffo, R.; Ossipov, D.; Dawson, J. Bisphosphonate nanoclay edge-site interactions facilitate hydrogel self-assembly and sustained growth factor localization. Nat. Commun. 2020, 11, 1365. [CrossRef] [PubMed]

36. Matsumoto, K.; Hayashi, K.; Murata-Hirai, K.; Iwasaki, M.; Okamura, H.; Minato, N.; Morita, C.T.; Tanaka, Y. Targeting Cancer cells with Bisphosphonate Prodrug. Chem. Med. Chem. 2016, 11, 2656-2663. [CrossRef] 
37. Danial, M.; Telwatte, S.; Tyssen, D.; Cosson, S.; Tachedjian, G.; Moad, G.; Postma, A. Combination anti-HIV therapy via tandem release of prodrugs from macromolecular carriers. Polym. Chem. 2016, 7, 7477-7487. [CrossRef]

38. Yu, T.; Zhuang, W.; Su, X.; Ma, B.; Hu, J.; He, H.; Li, G.; Wang, Y. Dual-Responsive Micelles with Aggregation-Induced Emission Feature and Two-Photon Absorption for Accurate Drug Delivery and Bioimaging. Bioconjugate Chem. 2019, 30, $2075-2087$. [CrossRef] [PubMed]

39. Liu, G.; Choi, K.Y.; Bhirde, A.; Swierczewska, M.; Yin, J.; Lee, S.W.; Park, J.H.; Hong, J.I.; Xie, J.; Niu, G.; et al. Sticky Nanoparticles: A Platform fore siRNA Delivery by a Bis(zinc(II)dipicolylamine)-Functionalized, Self-Assembled Nanoconjugate. Angew. Chem. Int. Ed. 2012, 51, 445-449. [CrossRef] [PubMed]

40. Su, J. Thiol-Mediated Chemoselective Strategies for In Situ Formation of Hydrogels. Gels 2018, 4, 72. [CrossRef]

41. Gevrek, T.N.; Cosar, M.; Aydin, D.; Kaga, E.; Arslan, M.; Sanyal, R.; Sanyal, A. Facile Fabrication of a Modular "Catch and Release" Hydrogel Iterface: Harnessing Thiol-Disulfide Exchange for Reversible Protein Capture and Cell Attachment. ACS Appl. Mater. Interfaces 2018, 10, 14399-14409. [CrossRef] [PubMed]

42. Pedrosa, S.S.; Gonçales, C.; Davis, L.; Gama, M. A novel Crosslinked Hyaluronic Acid Nanogel for Drug Delivery. Macromol. Biosci. 2014, 14, 1556-1568. [CrossRef] [PubMed]

43. Bae, M.S.; Yang, D.H.; Lee, J.B.; Heo, D.N.; Kwon, Y.-D.; Youn, I.C.; Choi, K.; Hong, J.H.; Kim, G.T.; Choi, Y.S.; et al. Photo-cured hyaluronic acid-based hydrogels containing simvastatin as a tissue regeneration scaffold. Biomaterials 2011, 32, 8161-8171. [CrossRef] [PubMed] 